\title{
Ultrasound imaging, a stethoscope for body composition assessment
}

\author{
Federico Ponti ${ }^{1}$, Antonio De Cinque ${ }^{1,2}$, Nicola Fazio ${ }^{3}$, Alessandro Napoli ${ }^{4}$, Giuseppe Guglielmi ${ }^{5,6}$, \\ Alberto Bazzocchi ${ }^{1}$
}

${ }^{1}$ Diagnostic and Interventional Radiology, IRCCS Istituto Ortopedico Rizzoli, Bologna, Italy; ${ }^{2}$ Department of Specialized, Diagnostic, and Experimental Medicine, University of Bologna, Sant'Orsola-Malpighi Hospital, Bologna, Italy; ${ }^{3}$ Technology Transfer Office, IRCCS Istituto Ortopedico Rizzoli, Bologna, Italy; ${ }^{4}$ Department of Radiologic, Oncologic and Pathologic Science, La Sapienza University of Rome, Rome, Italy; ${ }^{5}$ Department of Radiology, University of Foggia, Foggia, Italy; ${ }^{6}$ Department of Radiology, Scientific Institute "Casa Sollievo della Sofferenza" Hospital, Foggia, Italy

Correspondence to: Federico Ponti, MD. Diagnostic and Interventional Radiology, IRCCS Istituto Ortopedico Rizzoli, Via G. C. Pupilli 1, 40136 Bologna, Italy. Email: pontifederico83@gmail.com.

\begin{abstract}
Dysregulation of the human's energy balance, mediated by non-performing endocrine organs (liver, skeletal muscle and adipose tissue, above all), can be related to human metabolic disorders characterized by an impaired body composition (BC), such as obesity and sarcopenia. While it is possible to monitor the $\mathrm{BC}$ and its variations at different levels, the tissue-organ composition studies have been proven to provide the most clinically applicable information. Ultrasonography (US), a fast, non-invasive, low-cost and widely available technique, holds great potential in the study of BC, as it can directly measure muscles, organs, visceral and subcutaneous fat tissue in different sections of the abdomen and body, overcoming some limits of anthropometric evaluation and other imaging techniques. Purpose of this review article is to explore the technical aspects and the applied methods of US examination to assess the potential clinical role of this technique in the context of BC characterization, investigating four pivotal topics [abdominal fat compartments, subcutaneous adipose tissue (SAT), skeletal muscle, liver].
\end{abstract}

Keywords: Body composition (BC); ultrasound; technical aspects; metabolic disorders; tissue characterization; muscle; abdomen; liver; reference standard

Submitted Dec 14, 2019. Accepted for publication May 07, 2020.

doi: $10.21037 /$ qims-19-1048

View this article at: http://dx.doi.org/10.21037/qims-19-1048

\section{Introduction}

Fuel storage organs, such as liver, skeletal muscle and adipose tissues, determine fuel selection and delivery under strict control of neuroendocrine system. Dysregulation of this energy control is correlated with human metabolic disorders, which are typically characterized by an impaired body composition (BC), including obesity and sarcopenia. However how this control is being regulated for adaptive adjustments of systemic metabolism remains unknown.

According to the WHO, overweight and obesity are defined as abnormal or excessive fat accumulation in the body and they are usually classified by body mass index (BMI). Obesity is well known as a risk factor for metabolic disorders development, such as cardiovascular diseases (CVDs) and type 2 diabetes mellitus (T2DM) (1) and its prevalence is increasing throughout the world $(2,3)$. Although total body fat remains a physiological parameter of major significance, there is now a growing consensus over the clinical role of regional and differential quantification of precise fat tissue compartments. As a matter of fact, specific body fat distribution patterns associate with specific profiles of metabolic deregulation. Researches have showed a link between ectopic fat accumulation, including visceral fat, 
hepatic fat (steatosis) and cardiac fat, with an increased risk of hypertension, coronary heart disease and atherosclerosis as well as arterial and venous thrombosis (4-7).

In parallel the attention of scientific community has been focused on the evaluation of sarcopenia, a condition characterized by progressive and generalized reduction of skeletal muscle mass and strength, associated with an increased risk of adverse outcomes (disability, hospitalization, death), making this geriatric syndrome a major public health burden (8).

Although many tools are available to investigate BC at different levels of organization (Table 1), the latter is mainly studied and scanned by employing clinically available techniques, such as anthropometry (whole-body level), bioelectrical impedance analysis (BIA, bi-compartmental model) and dual-energy X-ray absorptiometry (DXA, tricompartmental model). In particular both DXA and BIA are techniques used in the assessment of $\mathrm{BC}$ at molecular level with the difference that DXA is based on a threecompartment model [distinguishing fat mass (FM), non-bone lean mass (LM) and bone mineral content (BMC)], while BIA is based on a two-compartment model (distinguishing FM and $\mathrm{LM}+\mathrm{BMC}$ ). Since fat, muscles and other deposits in which lipids accumulate are studied and considered, by definition, as tissues and organs, the organtissue level of organization is considered one of the most relevant in the field of $\mathrm{BC}$ clinical applications.

Computed tomography (CT) and magnetic resonance imaging (MRI) are precise imaging methods that are very well suited to the purposes of $\mathrm{BC}$ analysis. However, for safety and cost reasons, these techniques remain unsuitable for conducting large population and longitudinal studies. Ultrasonography (US) is a fast and non-invasive technique capable of directly measuring visceral adipose tissue (VAT) and subcutaneous adipose tissue (SAT) in different sections of the abdomen, also enabling the opportunity of directly assessing individual muscles or organs; this peculiarity allows US to overcome some limits of anthropometry and of conventional DXA and BIA technologies and, for these reasons, it holds great potential in studying BC. Moreover, US widespread availability and low cost, together with no ionizing radiation risks, make it the first-line diagnostic method for the evaluation of large cohort of patients in clinical settings $(9,10,13,14)$.

Aims of this review work are to describe the technical aspects and the latest methods of US examination in order to outline the role of this technology in the translation of BC studies to clinical routine; to facilitate reading this narrative review has been arranged in four topics (abdominal fat compartments, SAT, skeletal muscle, liver) each of which consisting of a short explanation of the topic, an ultrasound technique section and a clinical significance section.

\section{Abdominal fat compartments}

The most commonly measure adopted to assess obesity is BMI, defined as weight/(height) ${ }^{2}$. This index doesn't allow to distinguish body fat from LM (muscle compartment and $\mathrm{BMC}$ ), so it is an inaccurate parameter of BC assessment, overestimating fat in muscular people without providing information regarding its distribution $(15,16)$.

Waist circumference (WC) is often used as raw measurement of abdominal fat, however this evaluation system is unable to separate the effect of VAT from that of SAT (17), and lacks in accuracy as regards its correlation with cardiovascular $(\mathrm{CV})$ risk stratification, as described by several authors (18-21). A further limitation of the WC is that the use of this measure in isolation may underestimate or overestimate the health risks for tall and short individuals with similar WCs, because there is relatively strong evidence of an inverse association between height and health risks (22-24). There are at least five proposed cutoff thresholds for different sexes, races and countries, considering the height effect over the metabolic risk in different populations (25).

\section{Ultrasound technique}

The use of ultrasound for the assessment of abdominal adiposity dates back to the 90s (26) and, over the last three decades, it has emerged as a useful tool for measuring VAT. In general, when US technique is employed to assess BC, the parameters of visceral adiposity are measured using a probe, which is kept perpendicular to the skin while applying a light pressure on the abdomen with the hands, paying attention not to compress the layers of fat, with the subject in a supine position (arms at sides) at the end of a normal expiration, to avoid the misleading reduction of tissue compartments thicknesses $(13,14)$. Thus, considerable skill, training, and practice are necessary to produce reliable and valid results (see Table 2). Moreover obesity and noncompliance with fasting are two limiting factors in accuracy of measurements due to poor visualization of anatomical structures $(13,14)$.

US procedures for assessing abdominal adiposity are not 


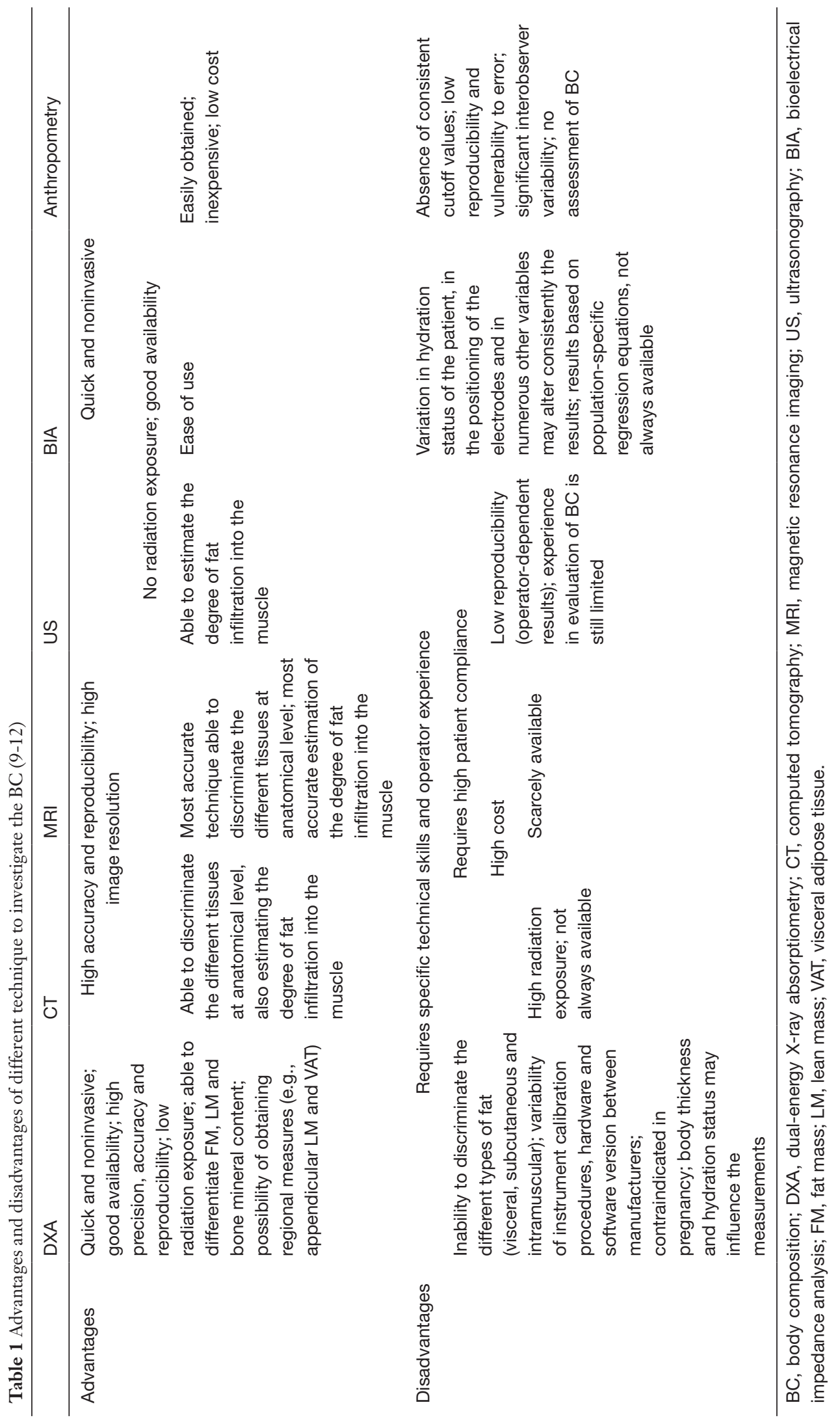


Table 2 Validation and reliability of main parameters of adiposity assessed by ultrasound

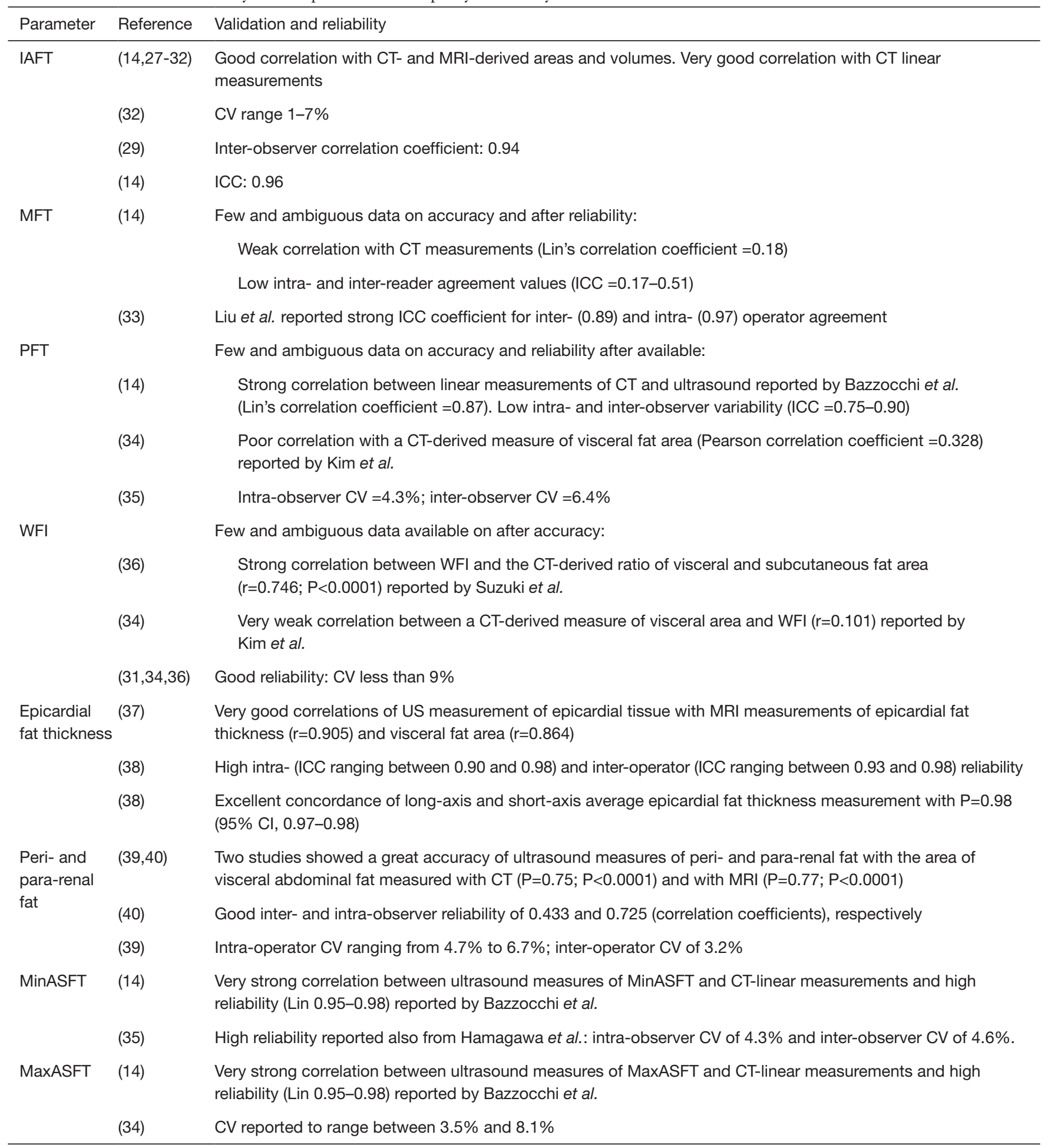

IAFT, intra-abdominal fat thickness; CT, computed tomography; MRI, magnetic resonance imaging; CV, coefficient of variation; ICC, intraclass correlation coefficient; MFT, mesenteric fat thickness; PFT, pre-peritoneal fat thickness; WFI, wall fat index; US, ultrasonography; MinASFT, minimum subcutaneous fat thickness; MaxASFT, maximum abdominal subcutaneous fat thickness. 


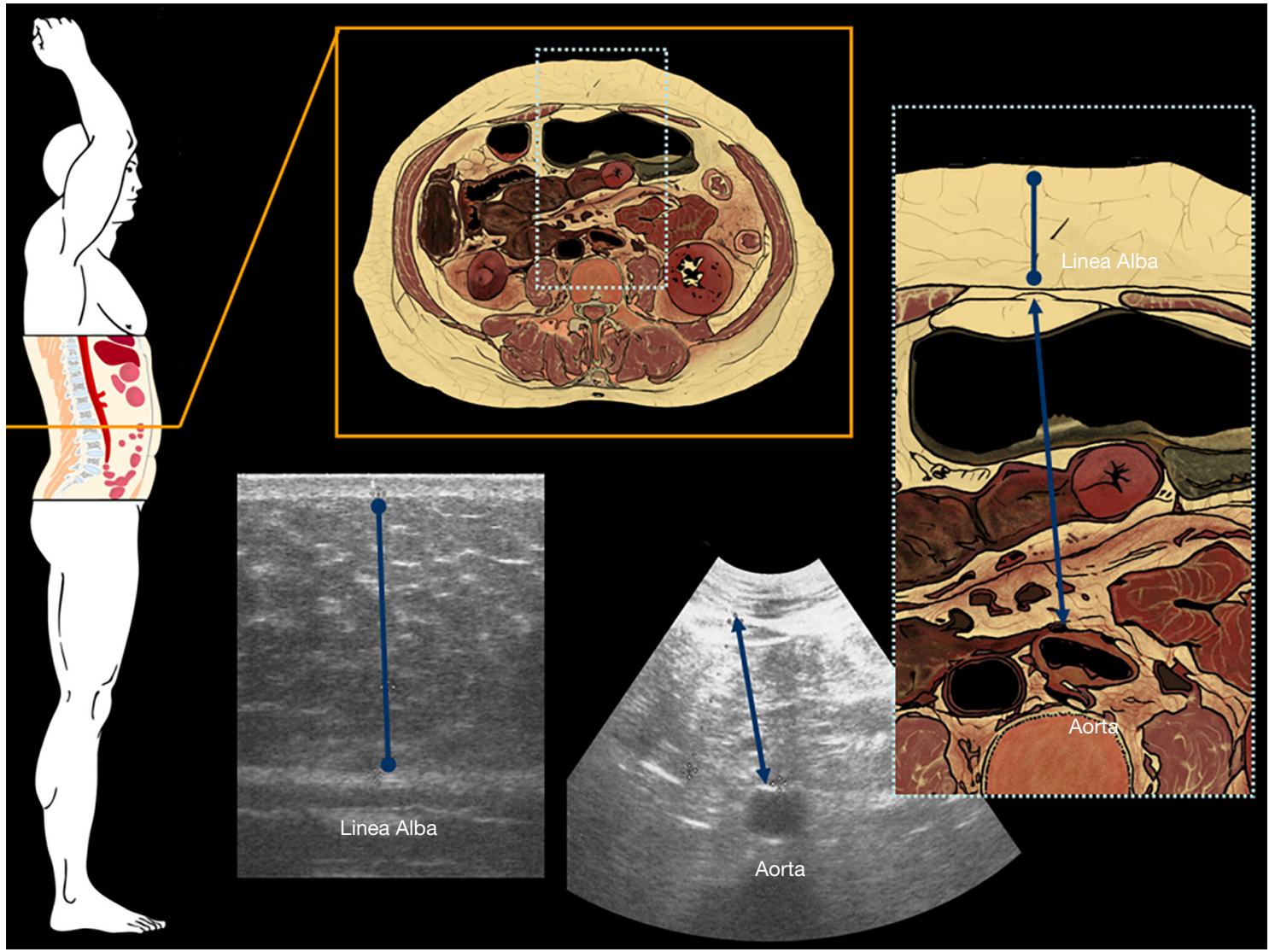

Figure 1 Anatomic representation of the abdominal sagittal section (on the left) and the abdominal axial section (on the center with its enlargement on the right) $2 \mathrm{~cm}$ above the umbilicus where are measured US MaxASFT (blue caliper with rounded tips) and intra-abdominal fat thickness (blue caliper with filled arrowheads). US, ultrasonography; MaxASFT, maximum abdominal subcutaneous fat thickness.

as clearly defined or standardized unlike other BC methods. In literature have been published detail anatomical placement, measurement technique, and pretesting guidelines for anthropometry, skinfolds and BIA, yet there is considerable variability for ultrasound frequencies and measurement sites (11). The following are the most used and shared measurements of visceral adiposity during the last three decades.

\section{Intra-abdominal fat thickness (IAFT)}

IAFT is one of the most useful measurement in adiposity ultrasound evaluation; this parameter is assessed adopting a convex probe (3.5-5 MHz), however there is no unanimous consensus on which anatomical measures should be considered as reference to be acquired by US: some authors measured IAFT as the distance between the anterior wall of the aorta and the posterior surface of linea alba, $2 \mathrm{~cm}$ above the umbilicus (Figures 1,2) $(13,26,34,41,42)$. Others have measured IAFT from the abdominal muscle to the anterior wall of a lumbar vertebra, to the psoas muscle, or to the posterior wall of the aorta (27-29), otherwise it has been evaluated as the distance between the peritoneum and the lumbar spine (30).

\section{Mesenteric fat thickness (MFT)}

MFT is measured with a convex probe on the area surrounding the umbilicus as the distance between the mesenteric leaves conventionally identified as a highly reflective peritoneal surfaces (Figure 2) (33).

\section{Pre-peritoneal fat thickness (PFT)}

PFT was firstly introduced by Suzuki et al. in 1993, as a component of the abdominal wall fat index (WFI) (36).

It is assessed with linear probe $(7.5 \mathrm{MHz})$, right below the xiphoid process with a longitudinal scan on the xiphoumbilical line, as the major distance between the 

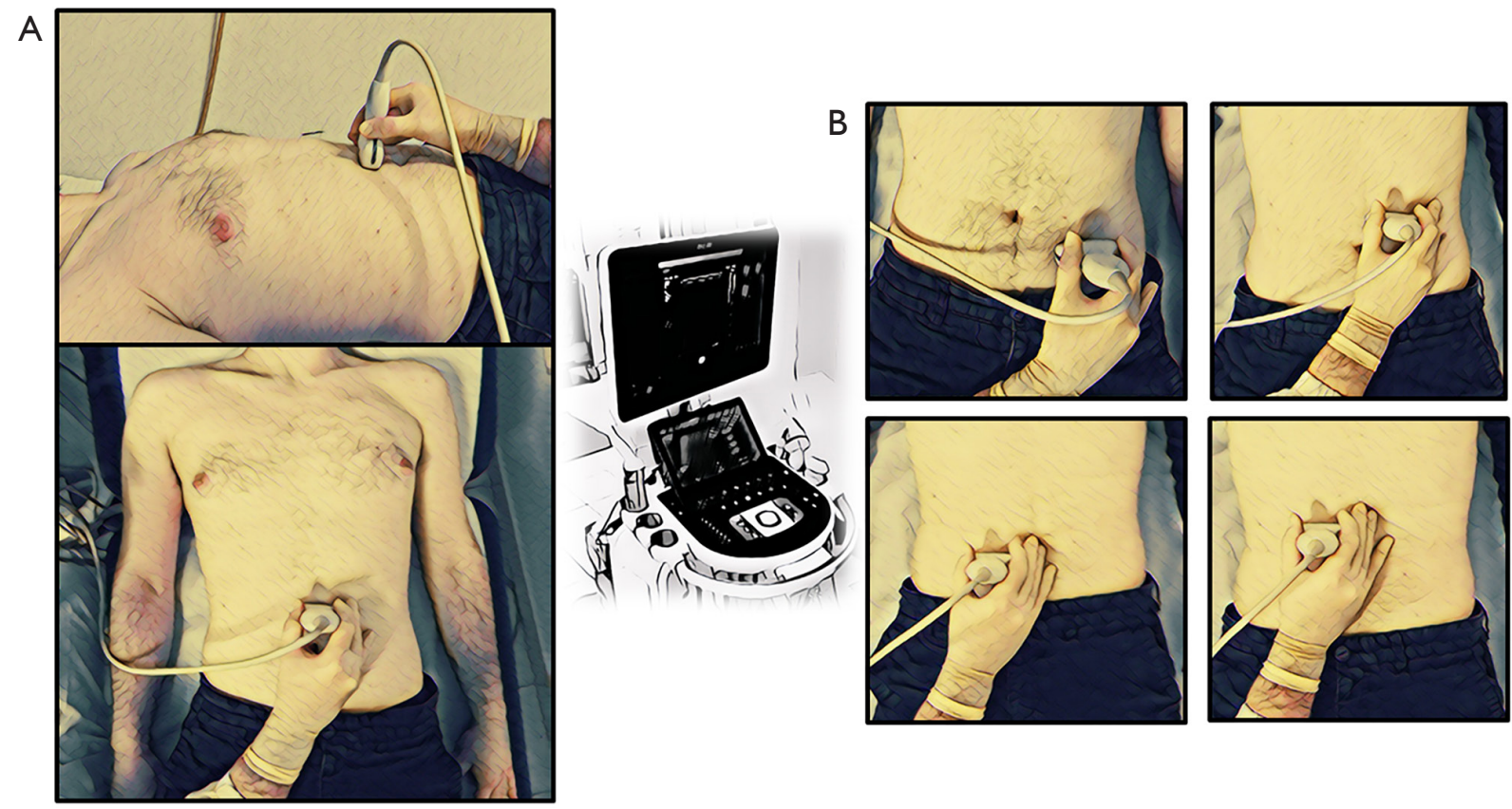

Figure 2 On the left (A) is represented the anatomical posture of ultrasound's probe in the evaluation of IAFT, while on the right (B) is represent represented the anatomical postures of ultrasound's probe in the evaluation of MFT. IAFT, intra-abdominal fat thickness; MFT, mesenteric fat thickness.

anterior surface of the peritoneum covering the liver to the posterior surface of linea alba (Figures 3,4).

It is not universally considered as a type of visceral fat since it directly drains from the systemic bloodstream rather than from the portal system $(31,33)$.

\section{Abdominal WFI}

The abdominal WFI is widely used to assess regional fat deposits. This measure, introduced by Suzuki et al. in 1993 (36) is calculated as the ratio of PFT to minimum abdominal subcutaneous fat thickness (MinASFT). Based on the WFI, obesity could be classified into visceral (WFI $>1$ ) or subcutaneous (WFI <1) type.

\section{Epicardial fat}

Epicardial fat is the visceral fat depot of the heart. The thickness of epicardial fat is usually assessed with subjects in left lateral decubitus position. Typically, 10 cycles of twodimensional parasternal views with long and short axes and 10 cycles of $M$-mode are necessary for precise evaluation. The thickness of epicardial fat appears as an echo-free area on the free wall of the right ventricle, which has the thickest layer of epicardial fat, both from long and short axis parasternal views (37).

\section{Peri- and para-renal fat}

Peri-renal fat is the adipose tissue surrounding the kidneys and lies between the outer surface of the renal parenchyma and the renal (Gerota's) fascia. Para-renal fat is a type of adipose tissue outside the Gerota fascia and accumulates mainly posteriorly and postero-laterally to each kidney. They are measured as distance between the inner side of the abdominal muscle and the surface of the kidney as mean of both sides values, employing a $3.5-5 \mathrm{MHz}$ probe, over a longitudinal scan with the surface of the kidney parallel to the skin (39).

\section{Clinical significance}

The adipose tissue located inside the abdomen and the thorax, known as VAT, has been reported as the most dangerous, being the major determinant of insulin resistance (IR), glucose intolerance, dyslipidemia, atherogenic lipid profile, endothelial damage and thrombophilia, that are all known predictors of CV risk (18), as well as its increase is associated with cognitive decrements (43).

Many authors found positive correlation of ultrasoundassessed VAT with clinical and laboratory markers. Kim et al. (34) and Stolk et al. (44), have shown that IAFT was 


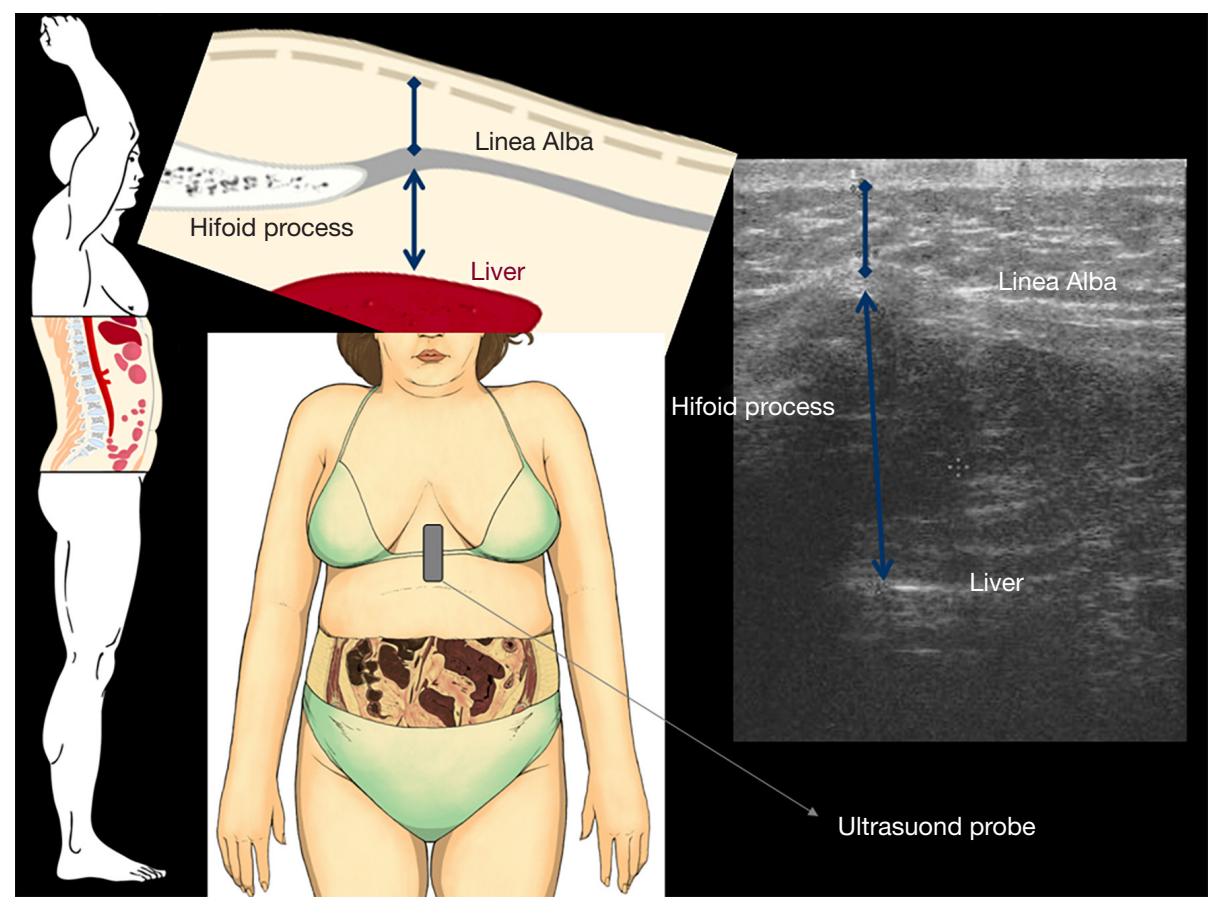

Figure 3 On the left are represented anatomic pictures of the abdominal sagittal section (with its enlargement in upper) and of the abdominal frontal section where MinASFT (blue caliper with diamond tips) and maximum preperitoneal fat thickness (blue caliper with arrowheads) have been measured with US. US, ultrasonography; MinASFT, minimum abdominal subcutaneous fat thickness.

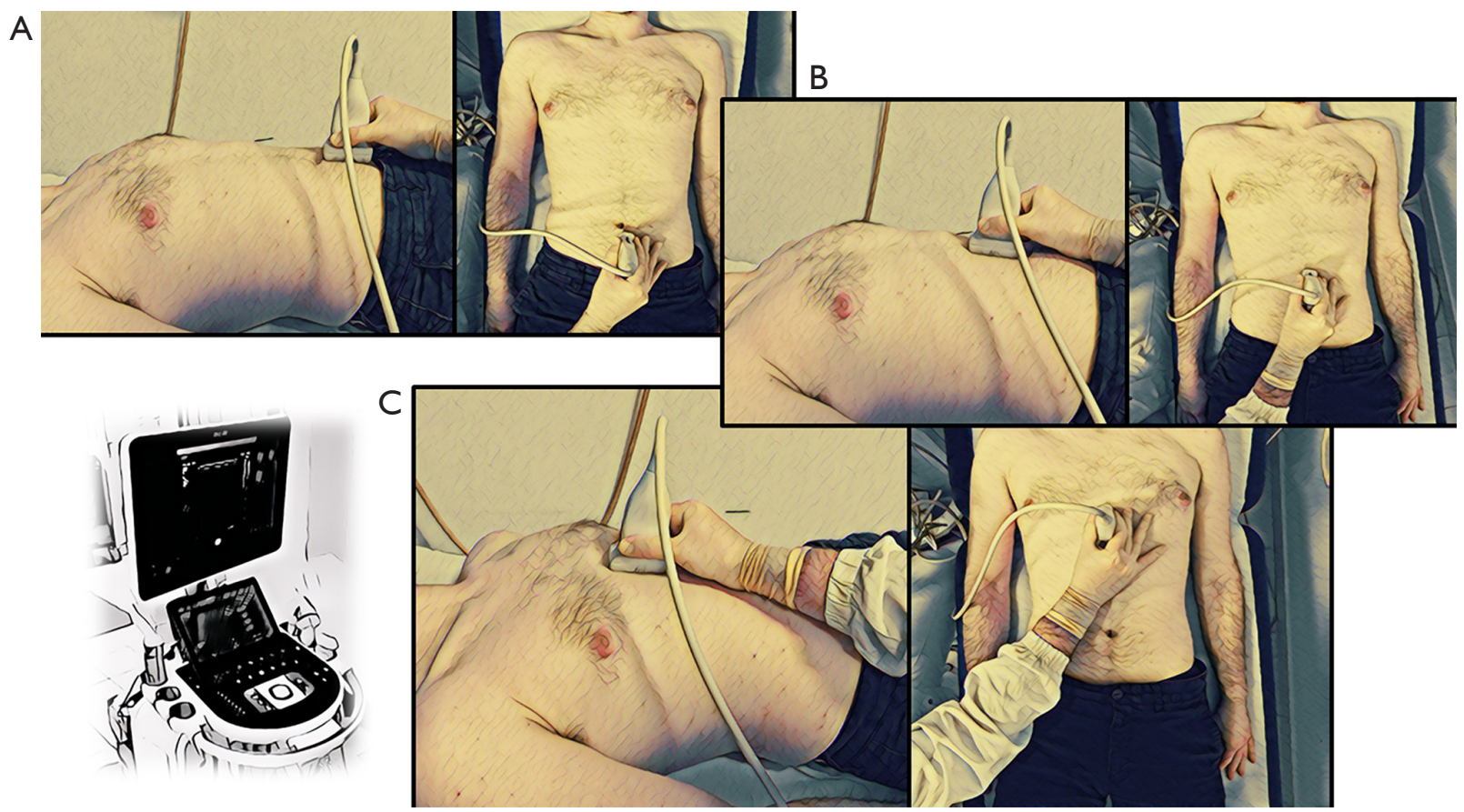

Figure 4 In the boxes with black border are represented the anatomical postures of ultrasound's probe in the evaluation of subcutaneous

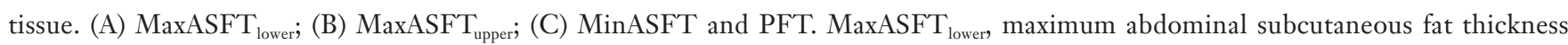
$2 \mathrm{~cm}$ below the umbilicus; MaxASFT ${ }_{\text {upper, }}$ maximum abdominal subcutaneous fat thickness $2 \mathrm{~cm}$ above the umbilicus; MinASFT, minimum abdominal subcutaneous fat thickness; PFT, pre-peritoneal fat thickness. 
correlated with cholesterol and triglyceride (TG) levels, fasting insulin levels, high-density lipoprotein (HDL) $(34,44)$, fasting glucose (44), IR and the carotid intimamedial thickness (IMT) (34).

A strong correlation between MFT and several clinical parameters of metabolic and CVDs has been evidenced by Liu et al.; such parameters include total cholesterol, lowdensity lipoprotein (LDL) cholesterol, TG, fasting glucose, glycate hemoglobin levels and systolic blood pressure in men, and TG and glycate hemoglobin levels in women $(31,33)$.

The amount of epicardial adipose tissue, significantly higher in subjects with metabolic syndrome (MS) than in subjects without MS, was related to LDL cholesterol levels directly associated with blood pressure, fasting glucose, inflammatory markers and inversely associated with insulin sensitivity (38).

In one of largest and recent study (45) that has measured VAT and SAT by US, Bertoli et al. found that VAT is strongly and independently associated to MS and its components. In addition, VAT has shown a stronger association than WC with high values of liver enzymes [alanine aminotransferase (ALT) and $\gamma$-glutamyl transferase (GGT)] and a similar association compared to WC with high uric acid (45), that have been recently related to MS (46-48). Moreover, VAT correlates equally or better than WC with clinical parameters, except for high blood pressure and low HDL (45). In 2018, Bellan et al. (18) found that VAT was strongly associated with BMI and WC over the full spectrum of BMI categories when measuring IAFT by US, although the strength of these associations was strong in obese patients and weak in subjects of normal weight. Moreover, the same research group evaluated that, by adding to the model the estimate of the VAT by ultrasound in relation to the BMI alone, a better prediction of the Framingham score, the vascular age and the homeostatic model assessment (HOMA)-IR can be obtained (17). Interestingly, Jena et al. (49) found significantly higher VAT thickness in women with polycystic ovary syndrome (PCOS) than healthy controls, and this correlated significantly with $\mathrm{CV}$ risk factors such as central obesity [WC and waist-tohip ratio (WHR)], BMI, and blood pressure, suggesting that VAT may be an independent predictor of CV risk among women with PCOS.

Another promising field of application is the use of US-assessed VAT in early pregnancy. Thaware et al. (50) observed that VAT measurement in early pregnancy was independently associated with risk of gestational diabetes mellitus (GDM) and it could be a potential clinical tool for improving the sensitivity of selective screening for GDM.

Along time, several other studies (51-54) found a correlation between measures of US-assessed VAT and clinical parameters of metabolic and CVDs, and these data suggest that visceral abdominal fat plays an important role in the development of cardiometabolic risk factors.

To our knowledge only Bazzocchi et al. (55) has investigated US assessed reference values of visceral adiposity in adult healthy people, while only one study identified cutoff points of intra-abdominal fat values associated with a greater chance of MS in adolescents (age 14-19) (56) (Table 3); further robust studies are needed to implement its use in routine clinical practice.

\section{Subcutaneous adipose tissue}

SAT has been often assessed using skinfolds, but the accuracy obtainable with this technique is limited because skin and SAT are measured together in a compressed state (57), by the lack of correction for elastic properties of tissue between individuals and there is also a practical limitation in the skinfold width that can be measured using a caliper in people with high body FM (58).

Due to high accuracy and precision US can be used to measure SAT patterning and its longitudinal changes with the best sensitivity so far among other methods in different population (e.g., in athletes, where accurate BC assessment is important to avoid health risks in weightsensitive sports) (57).

\section{Ultrasound technique}

In the abdomen, two specific subcutaneous thicknesses are often considered: MinASFT and maximum abdominal subcutaneous fat thickness (MaxASFT) (see Table 2), both evaluated in the same condition of visceral adiposity parameters $(14,30,33,36)$.

MinASFT is measured with linear probe $(7.5 \mathrm{MHz})$ in the same anatomic region of the maximum pre-peritoneal fat, as the distance between the anterior surface of linea alba and the fat-skin barrier (Figures 3,4) $(13,14)$. Like preperitoneal fat, MinASFT is a part of the abdominal WFI and it was first described by Suzuki in 1993 (36).

Regarding MaxASFT, Liu et al. (33) measured it as the distance between the linea alba and the fat-skin barrier, transversely placing a linear transducer perpendicular to the skin, right in the midline of the abdomen, between the 
Table 3 Reference values for healthy Italian people

\begin{tabular}{|c|c|c|c|}
\hline Age & IAFT (cm) & MFT (cm) & PFT (cm) \\
\hline $18-30^{\star \star}$ & M: $3.86 \pm 1.12 ; F: 3.01 \pm 1.13$ & M: $0.60 \pm 0.26 ; F: 0.54 \pm 0.17$ & $\mathrm{M}: 1.53 \pm 0.42 ; \mathrm{F}: 1.29 \pm 0.35$ \\
\hline $31-40^{\star \star}$ & M: $3.93 \pm 1.44 ; F: 3.22 \pm 1.07$ & M: $0.61 \pm 0.29 ; F: 0.58 \pm 0.30$ & $M: 1.56 \pm 0.47 ; F: 1.30 \pm 0.42$ \\
\hline $41-50^{\star \star}$ & 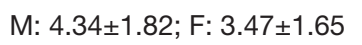 & M: $0.63 \pm 0.24 ; F: 0.63 \pm 0.27$ & $M: 1.63 \pm 0.63 ; F: 1.45 \pm 0.55$ \\
\hline $61-70^{\star \star}$ & M: $5.69 \pm 1.81 ; F: 3.59 \pm 1.67$ & M: $0.77 \pm 0.29 ; F: 0.50 \pm 0.12$ & $M: 1.83 \pm 0.65 ; F: 1.41 \pm 0.35$ \\
\hline
\end{tabular}

*, Median values reported by Novais et al. (56). ${ }^{*}$, Reference values for healthy Italian people reported by Bazzocchi et al. (55). IAFT, intra-abdominal fat thickness; MFT, mesenteric fat thickness. PFT, pre-peritoneal fat thickness; M, males; F, females.

xiphoid process and the umbilicus while in other studies MaxASFT was measured $1 \mathrm{~cm} \mathrm{(34)} \mathrm{and} 5 \mathrm{~cm}$ (30) above the umbilicus, or at two levels $(2 \mathrm{~cm}$ above and $2 \mathrm{~cm}$ below the umbilicus) as visualized in Figures 1,4 (14).

Considering the whole body, a standardized, semiautomatic, US SAT thickness evaluation technique with measurements at a set of eight standardized sites (upper abdomen, lower abdomen, lateral thigh, erector spinae, distal triceps, brachioradialis, front thigh and medial calf) has recently been proposed in order to maximize both accuracy and reproducibility (57). To avoid measurements errors it is recommended to use a thick layer $(5 \mathrm{~mm})$ of US gel between the probe and the skin due to the compressibility of adipose tissue, without any pressure on the US probe, and to set speed of sound at $1,450 \mathrm{~m} / \mathrm{s}$ instead of $1,540 \mathrm{~m} / \mathrm{s}$ used in conventional diagnostic US systems (59). Speed of sound allows to calculate the distance from the probe to the boundary between two tissues: this parameter is of utmost importance as in fat sound speed is substantially lower $(1,450 \mathrm{~m} / \mathrm{s})$ than e.g., muscle and skin (60), so in thick layers of fat tissue the correct choice of sound speed $(1,450 \mathrm{~m} / \mathrm{s})$ predominantly determines the accuracy. Not correctly setting this parameter leads to a measurement error of about $6 \%$ and even a small deviation of only $15 \mathrm{~m} / \mathrm{s}(1 \%)$ generates a thickness measurement error of $1 \%(59,61)$.

At all measurement sites, subcutaneous fat is recorded as the perpendicular distance between the upper edge of the dermal/adipose interface and the upper edge of the adipose/ muscular interface $(13,14)$.

Although the scan is a simple procedure, the interpretation is relative difficult and subjective. First, fascia between superficial and depth SAT could be mistaken for the boundary layer between subcutaneous fat and muscle.
The operator must be able to identify interfaces, particularly the adipose-muscle interface, and accurately measure the subcutaneous tissue layer of interest. Additionally, pressing the transducer onto the patient's skin with too much force will significantly reduce the SAT thickness, until a reduction by $25-37 \%$ of SAT layer, as described by Toomey et al. (58).

\section{Clinical significance}

The contribution of SAT in the development of CV- and obesity-related diseases is controversial (protective or detrimental role depending on the authors), as discussed below $(45,62-65)$.

In a recent study, Bertoli et al. (45) evaluated not only the SAT relation with MS and its components alone, but also the joint contribution of SAT and VAT to MS. They found that SAT was independently associated with MS, and the association of SAT and VAT with MS was greater when they were considered together than when they were used alone. Moreover, SAT was independently associated also with high blood pressure and high ALT.

Other authors (65) have shown that subcutaneous fat is not associated with a linear increase in the prevalence of all risk factors among the obese; most striking, they found that linear trends for TGs decrease with increasing SAT in those with the most visceral fat, suggesting that subcutaneous fat could be a protective fat depot.

In a large and interesting study with a long median follow-up time (4.43 years), Kim et al. (66) showed that baseline SAT was significantly higher in the subjects who experienced regression of their nonalcoholic fatty liver disease (NAFLD) during follow-up period, than in the subjects who did not experience regression, regardless of their baseline VAT, providing a novel longitudinal evidence 
Table 4 Reference values for healthy Italian people

\begin{tabular}{llll}
\hline Age & \multicolumn{1}{c}{ MinASFT $(\mathrm{cm})$} & MaxASFT $_{\text {upper }}(\mathrm{cm})$ & MaxASFT $_{\text {lower }}(\mathrm{cm})$ \\
\hline $18-30$ & M: $0.71 \pm 0.28 ; F: 0.78 \pm 0.31$ & M: $1.48 \pm 0.76 ; F: 1.73 \pm 0.73$ & M: $1.68 \pm 0.78 ; F: 2.00 \pm 0.85$ \\
$31-40$ & M: $0.63 \pm 0.28 ; F: 1.05 \pm 0.71$ & M: $1.42 \pm 0.65 ; F: 1.97 \pm 1.16$ & M: $1.49 \pm 0.58 ; F: 2.24 \pm 1.26$ \\
$41-50$ & M: $0.77 \pm 0.30 ; F: 1.16 \pm 0.56$ & M: $1.71 \pm 0.69 ; F: 2.26 \pm 0.91$ & M: $1.80 \pm 0.78 ; F: 2.43 \pm 0.93$ \\
$51-60$ & M: $0.81 \pm 0.32 ; F: 0.92 \pm 0.41$ & M: $1.82 \pm 0.65 ; F: 1.74 \pm 0.72$ & M: $1.91 \pm 0.78 ; F: 2.01 \pm 0.76$ \\
$61-70$ & M: $0.78 \pm 0.28 ; F: 0.94 \pm 0.34$ & M: $2.09 \pm 0.77 ; F: 2.04 \pm 0.70$ & M: $2.39 \pm 1.61 ; F: 2.47 \pm 0.93$ \\
\hline
\end{tabular}

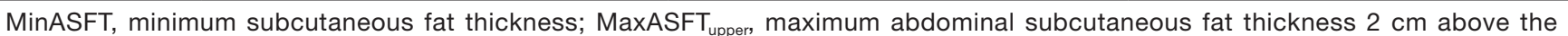

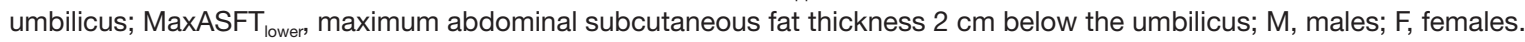

that SAT might be a possible metabolic protective factor for metabolic diseases, including NAFLD.

Jung et al. (67) demonstrated that, only in male in patients with T2DM, SAT was inversely associated with carotid intima-media thickness after adjustments for BMI and other traditional or non-traditional CVD risk factors, showing a significant gender effect on the correlation between SAT and CIMT. Bazzocchi et al. investigated MinASFT and MaxASFT values (shown in Table 4) in 250 healthy Italian people of different age groups (55) to identify cut-off values that could be used in clinical practice, although further studies involving other populations are needed as well as for abdominal fat compartments.

\section{Skeletal muscle}

Another big chapter in the US assessment of BC is the evaluation of the skeletal muscle. As established by EWGSOP2 sarcopenia "is a progressive and generalised skeletal muscle disorder that is associated with increased likelihood of adverse outcomes including falls, fractures, physical disability and mortality" (68).

The three core criteria of low muscle strength, low muscle mass (quantity or quality) and poor physical performance can be used both in the diagnosis of sarcopenia and in the assessment of its severity, with low muscle strength alone indicating probable sarcopenia, associated loss of muscle mass indicating sarcopenia and the presence of all three conditions indicating severe sarcopenia.

Recently a systematic review and meta-analysis by Beaudart et al. (8) has made a clear synthesis of the outcomes of sarcopenia, evaluating its clinical and socioeconomic consequences.

According to this meta-analysis (8), sarcopenia patients face a four times higher risk of mortality and a three times higher risk of functional decline or functional disability than non-sarcopenic subjects.

Despite the adverse impact of sarcopenia on the individual and their carers, the condition remains poorly understood and inconsistently diagnosed and managed. The diagnostic algorithm suggested by the EWGSOP2 assesses muscle mass, strength and performance. However, many of the relevant measurement techniques for assessing muscle mass have numerous flaws that make them unsuitable for routine use in frail older adults.

When the target sarcopenic population is typically frail, elderly and immobile, the imaging technique must be easily accessible, both geographically and physically, and in this regard ultrasound presents an advantage over other methods (Table 1).

US can play an important role in this developing research field, providing the opportunity to assess muscle thickness, marker of muscle quantity, and muscle echostructure, marker of muscle quality (including muscle echogenicity and pennation angle (PA), i.e., the angle in which muscles fibers are positioned), along with all US-associated benefits (noninvasive, low cost, portability, etc.).

\section{Tecbnique}

Several methodological approaches have been used among patient populations in the study of muscle (69) but, nowadays, no standardized protocol for the assessment of skeletal muscle has been established. In particular, a definitive agreement about which muscle group should be measured has not been reached.

The most commonly adopted methods are the measure of quadriceps muscle layer thickness (QMLT), rectus femoris cross-sectional area (RF CSA), and RF thickness (69-75): a single landmark (i.e., RF muscle thickness and 


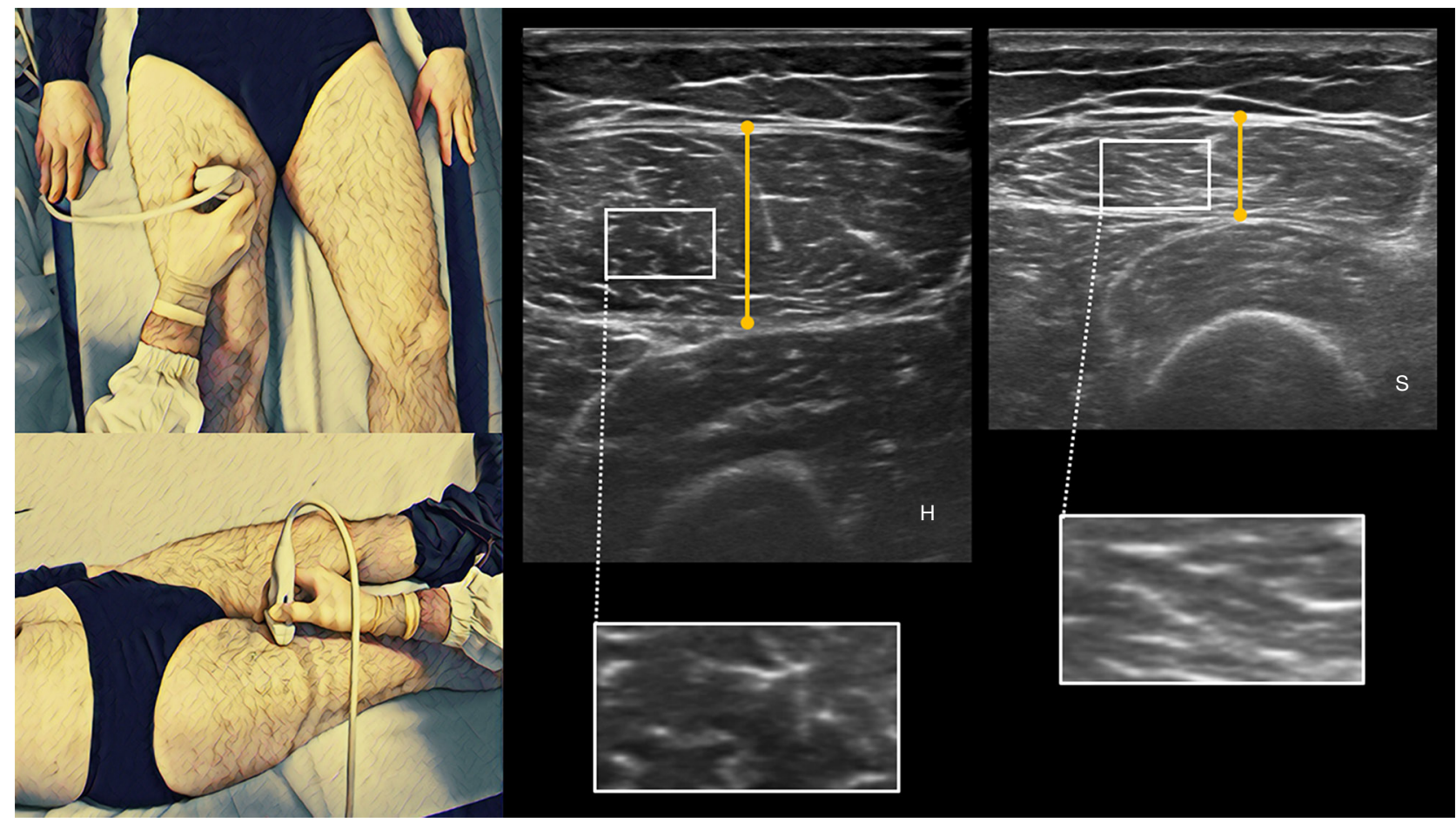

Figure 5 On the left is represented the anatomical posture of ultrasound's probe in the evaluation of RF muscle thickness; on the right are represented ultrasound images of healthy younger $(\mathrm{H})$ and sarcopenic older adult $(\mathrm{S})$ with their related differences of muscle echogenicity depicted in enlargements. RF, rectus femoris.

RF CSA), two landmarks (i.e., QMLT) or three or more landmarks can be analyzed (69).

Alongside measures of muscle mass, an important role is played by the quality of muscle that can be assessed by measuring the PA and echo intensity (EI) of the muscle (76,77).

$\mathrm{RF}$ muscle thickness is measured half-way along the line from the anterior-superior iliac spine to the superior border of the patella (75): the scan is performed by placing the transducer oriented in the transverse plane perpendicular to the skin in correspondence of the largest muscle diameter with the patient in supine position with arms and legs extended and muscles completely relaxed, measuring the distance between the superficial and the deep fascia, with none or minimal transducer compression on the skin and a suitable amount of ultrasound gel (Figure 5) $(69,75,76)$. Other authors, like Ema et al. (78), measured RF muscle thickness at approximately $60-70 \%$ of the thigh length, from the popliteal crease to the greater trochanter, corresponding to the muscle belly of RF, with a longitudinal scan, applying the lowest possible probe compression and with patient in supine position.
RF CSA measures are taken with the US transducer placed perpendicular to the long axis of the thigh on its superior aspect, three-fifths of the distance from the anterior superior iliac spine to the superior patellar border because this is the highest point in the thigh that can be displayed in a single field within the entire cross-section of the femoral rectum (Figure 6) (70). The patient has to be in supine position and minimal compression shall be exercised by the US transducer on the skin (70).

Measurement of QMLT combines the thickness of the $\mathrm{RF}$ and of the vastus intermedius muscles and it is calculated as the distance between the upper margin of the femoral bone and the superficial fascia of the RF (subcutaneous fat-muscle interface). QMLT is calculated by taking the measurement at the border between the lower third and upper two-thirds between the anterior-superior iliac spine and the upper pole of the patella, and at the mid-point between the ASIS and the upper pole of the patella, with the patient in a supine or standing position and maximal transducer compression on the skin (69,71,79-81). Right and left quadriceps are assessed and then the average of these four readings over the right and left legs (two at each 


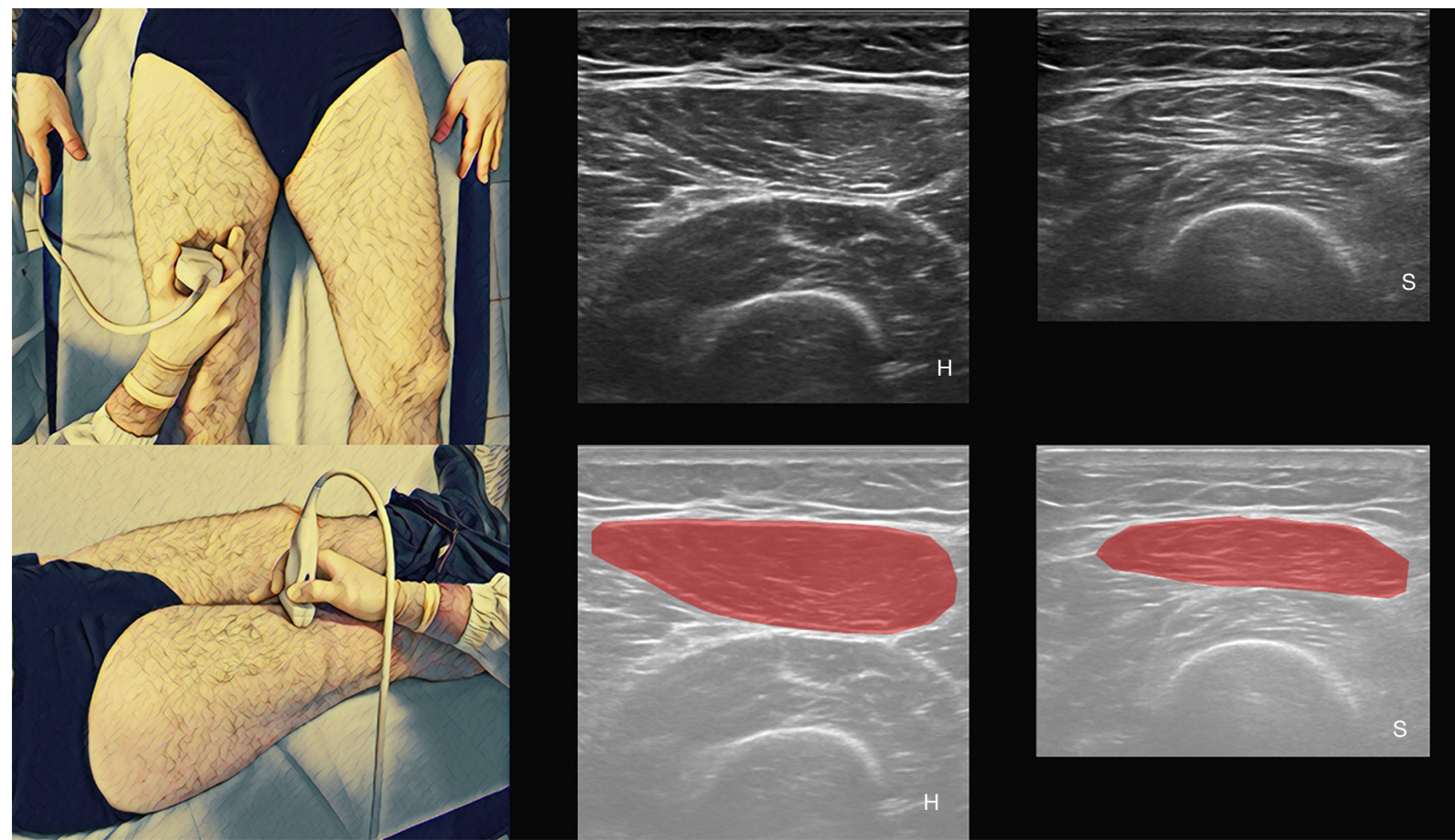

Figure 6 On the left is represented the anatomical posture of ultrasound's probe in the evaluation of RF CSA; on the right are represented ultrasound images of healthy younger $(\mathrm{H})$ and sarcopenic older adult $(\mathrm{S})$. RF CSA, rectus femoris cross-sectional area.

site) is done $(71,79)$. In some studies, QMLT is measured only at the mid-point between the ASIS and the upper pole of the patella $(80,81)$.

Other authors $(82,83)$ have used three or more landmarks; for example, Baldwin et al. (82) used acromiale, radiale, stylion, trochanterion, tibiale laterale sites (with patient in supine position and none transducer compression) while Sanada et al. (83) used nine sites in total (lateral forearm, anterior and posterior upper arm, abdomen, subscapula, anterior and posterior thigh, anterior and posterior lower leg) with patient in standing position $(83,84)$ and none transducer compression (83).

Reference values in healthy people for RF muscle thickness $(75,78,85)$, RF CSA $(70,85)$ QMLT $(71,77)$, PA (76) and EI (76) are shown in Table 5. PA is defined as the angle between muscle fibers (that run obliquely to the axis of pull) and their inserting intramuscular tendon (deep aponeurosis) (86). This parameter describes the muscle architecture and it is related to muscle quality (and strength) as the larger the PA, the more contractile material can be contained within a certain volume $(76,87)$. In muscles where the orientation of the fibers is almost parallel to their fascia (e.g., RF), the PA could be difficult to measure and not determinable (76). Its measure can be taken with a US longitudinal scan in the same place of RF thickness parameter, keeping the transducer compression on the skin as low as possible and using a suitable amount of ultrasound gel (Figure 7) (88).

Quantitative analysis of EI can be achieved by computeraided gray-scale analysis using grayscale histogram offered by several software and calculating the mean EI (a number between 0 and 255, where black $=0$ and white $=255$ ) of a region of interest in the selected muscle, such as a transversal scan of RF thickness (Figure 5) (76,77).

The validation and reliability studies of the literature demonstrated high values of ICC of thickness measures and RF CSA both in old and young people; on the other hand PA and EI parameters have shown low to moderate reliability as depicted in Table 6 (76). A further consideration is the repeatability of measures between different US equipment: while measurement of muscle thickness does not depend on US device, EI values is influenced by ultrasound system hardware and software and is therefore different for each US device used, so reference EI values can only be used with the same US device and settings. Pillen et al. (89) calculated an equation to convert and make 
Table 5 Reference values in healthy people detected with US

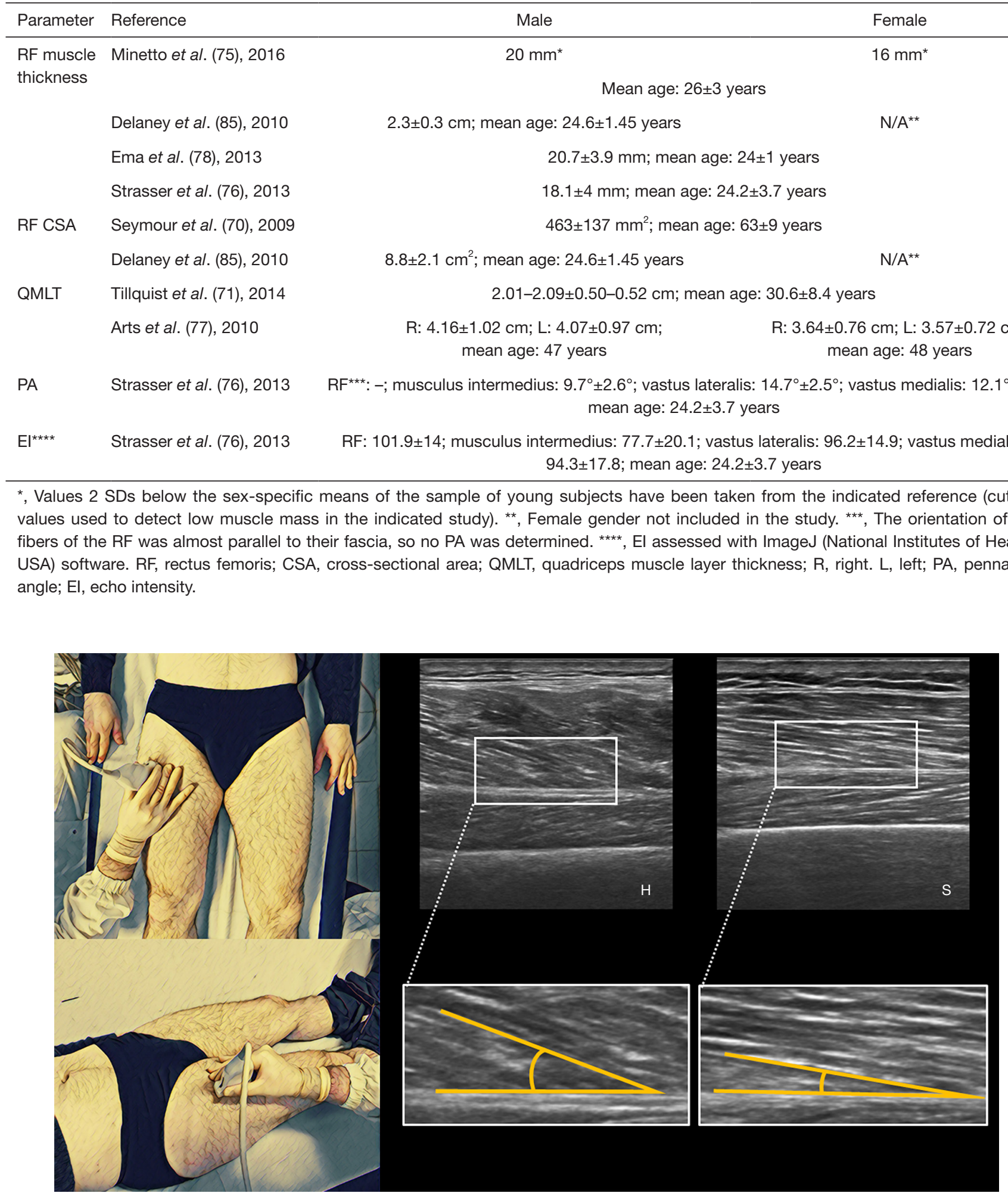

Figure 7 On the left is represented the anatomical posture of ultrasound's probe in the evaluation of vastus lateralis muscle's PA; on the right are represented ultrasound images of healthy younger $(\mathrm{H})$ and sarcopenic older adult $(\mathrm{S})$. PA, pennation angle. 
Table 6 Reliability of main parameters of muscle BC assessed by ultrasound

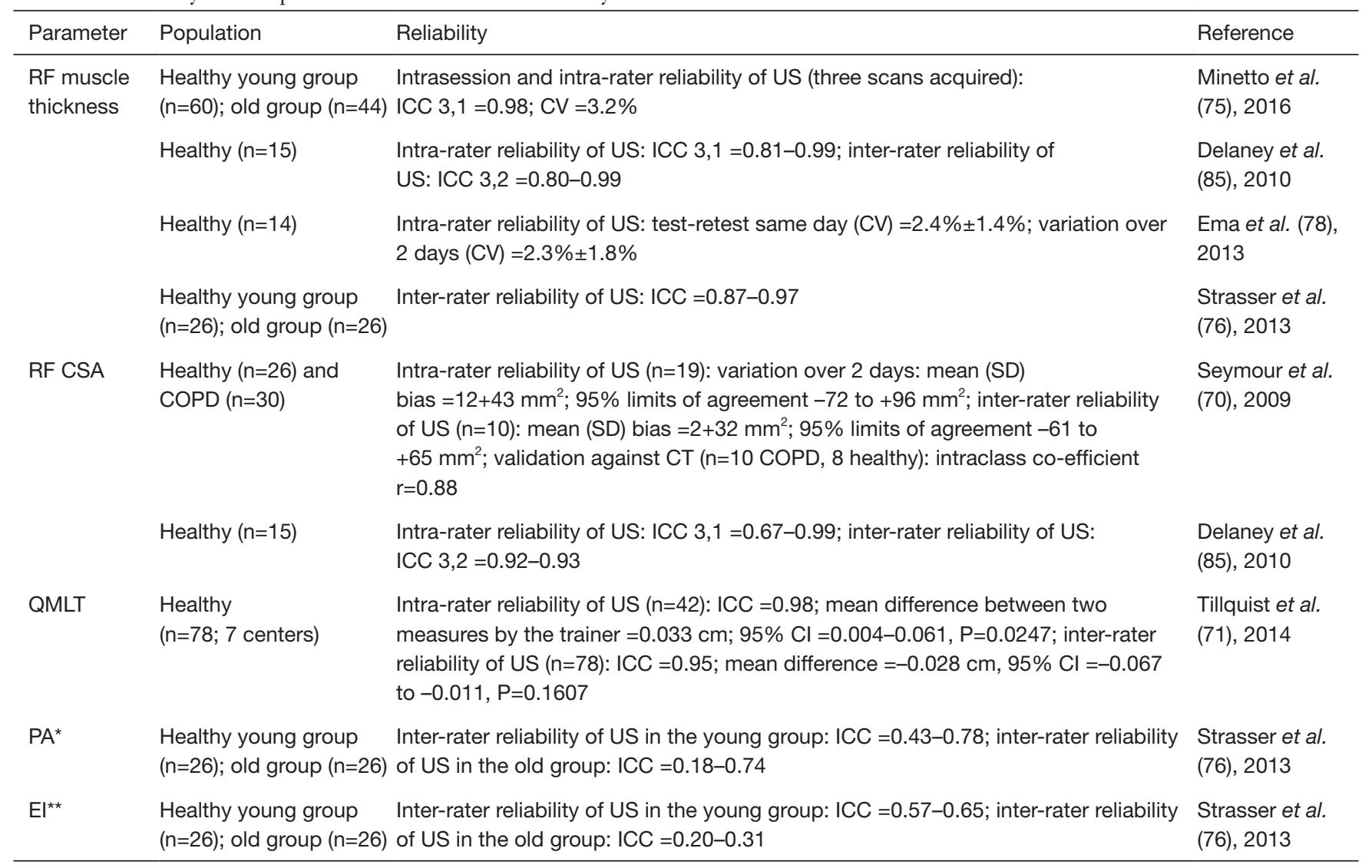

*, Assessed in all muscles of musculus quadriceps except for RF due to the orientation of its fibers almost parallel to their fascia. ${ }^{*}$, Assessed in all muscles of musculus quadriceps. RF, rectus femoris; BC, body composition; US, ultrasonography; ICC, intraclass correlation coefficient; CV, coefficient of variation; CSA, cross-sectional area; COPD, chronic obstructive pulmonary disease; QMLT, quadriceps muscle layer thickness; PA, pennation angle; El, echo intensity.

reliable muscle EI values obtained between different US devices in a healthy control group. However they found a higher variability between the US devices for EI values $>70$ so in patients with high muscle EI, repeated measurements with different US devices might not be able to reliably assess muscle quality changes over time (89).

\section{Clinical significance}

The use of ultrasound to assess sarcopenia has been constantly increasing due to its known advantages and motivated by several studies in different clinical settings $(70,71,90)$.

Puthucheary et al. (91) found that, among critically ill patients in an intensive care unit (ICU), muscle wasting measured by CSA, occurred early and rapidly during the first week of critical illness and was more severe among those with multiorgan failure compared with those with single organ failure.

Proximal muscles of the lower limb are preferentially affected by thickness loss than distal muscles (75), while the upper extremity muscles are less affected by aging (92). In a recent study, Ata et al. (90) found that abdominal [rectus abdominis (RA)] and thigh muscles (RF) were thinner in the older subjects than the younger ones, consistent with previous findings, and that they were affected earlier, together with a higher rate of decline, than total muscle mass. Gait speed (a parameter of physical performance) was associated with RF muscle thickness (90), suggesting that the regional assessment of muscle mass should be used to confirm the diagnosis of sarcopenia in subjects with low grip strength, or for predicting gait speed when could not be evaluated.

An interesting study by Strasser et al. (76) investigated 
with US not only dimensional changes but also changes in muscle architecture-echostructure (by measuring PA and EI) during ageing in all muscles of quadriceps and their association with skeletal muscle strength in the elderly. They found a significant reduced muscle thickness of all muscles of quadriceps, especially the RF, in the old group compared to the young group. Moreover all muscles investigated had a direct influence of maximum voluntary contraction (MVC) force but, after multiple regression analysis, only thickness of musculus vastus medialis in the old group and thickness of musculus vastus medialis and musculus intermedius in the young group demonstrated significant correlation with MVC (76).

Increased EI on an ultrasound image of skeletal muscle during ageing indicates changes in muscle quality, including raise of intramuscular fibrous and adipose tissues $(76,93)$.

Fukumoto et al. (93) and Watanabe et al. (81) reported that muscle quality assessed with EI correlated with muscle strength in middle-aged elderly women (93) and men, independently of muscle thickness (81), although other authors reported opposite results (76). As the matter of fact Strasser et al. (76) and Arts et al. (77), although they found a significant EI increase in elderly group, didn't find a significant correlation between EI and MVC in the older patient group. This discrepancy, as suggested by the authors (76), may be due to the different US scan plane adopted for EI determination (longitudinal $v s$. transverse). In addition to those results, a significant association has been reported between the EI value of anterior thigh muscles and functional mobility, indicating that muscle composition affects physical function in the old people (94). A clinical setting has been analyzed by Ye et al. (95): they found a significantly higher EI of the RF in all stages of chronic obstructive pulmonary disease (COPD) patients than in age-matched non-COPD subjects in addiction to an independent correlation of this US parameter with health-related quality of life (95). Investigations of PA values revealed its decrease with age $(76,96)$, in particular of musculus vastus lateralis and medialis (76), although without significant influence on MVC (76).

One of the major limitation of US in the study of skeletal muscle is the wide variability in body size-composition among populations. In fact, the cut-off values for detection of low muscle mass established in a specific ethnic group cannot be applied to other groups (75).

Arts et al. (77) and Minetto et al. (75) proposed a panel of skeletal muscles cut-off values by US to identify low muscle mass both in men and women of different age, although reference cut points are still lacking in many populations, including critically ill patients.

Nowadays thickness measurements of musculus quadriceps have shown encouraging results in the evaluation of the skeletal muscle mass and strength and could be a valid tool for diagnosis and follow-up of sarcopenia, while EI and PA parameters need to be further substantial investigated. The lack of standard evaluation criteria (parameters to consider, how to take them and reference values in healthy and sarcopenic population) currently represent the main limitation of US in the assessment of skeletal muscle.

\section{Liver}

Hepatic steatosis (HS) is the term used to describe cytoplasmatic micro-, macro- or mixed vesicular incorporation of triacylglycerols (TAGs) into hepatocytes (97). Alcoholic liver disease and NAFLD are the most common conditions associated with fatty liver (98).

According to the guidelines of the American Association for the Study of Liver Diseases the definition of NAFLD requires that there is evidence of $\mathrm{HS}$, diagnosed either by imaging or by histology and there are no causes for secondary hepatic fat accumulation such as significant alcohol consumption, use of steatogenic medication or hereditary disorders (99). NAFLD is associated with metabolic risk factors reflecting the MS and is becoming the most common cause of chronic liver diseases in Western countries, with a prevalence for adults in Western countries of $20-30 \%$ (100). HS can be isolated (majority of patients) or associated with hepatitis-non-alcoholic steatohepatitis (NASH). NASH determine hepatocellular injury (ballooning) and inflammation and can progress to cirrhosis through the development of fibrosis and lastly hepatocellular carcinoma (101).

\section{Technique}

Liver biopsy is the gold reference standard method for the HS assessment $(102,103)$ and it is the only procedure that can reliably differentiates NAFLD from NASH (104). However, its intrusiveness and other drawbacks (subjective visual estimation, small tissue samples) limits its broad application in clinical practice and epidemiological studies. MRI proton density fat fraction (MRI-PDFF) represents the reference standard among noninvasive technique $(105,106)$ although it is not widely available and expensive.

Based on Clinical Practice Guidelines by EASL-EASD- 
Table 7 Qualitative steatosis grading by abdominal ultrasound (121)

\begin{tabular}{ll}
\hline Grade & Description \\
\hline 0 & No steatosis; normal echogenicity of liver parenchyma; normal visualization of diaphragm and intrahepatic blood vessels \\
1 & $\begin{array}{l}\text { Mild steatosis; slightly increased echogenicity of liver parenchyma; normal visualization of diaphragm and intrahepatic blood } \\
\text { vessels }\end{array}$ \\
& $\begin{array}{l}\text { Moderate steatosis; markedly increased echogenicity of liver parenchyma; slightly impaired visualization of diaphragm and } \\
\text { intrahepatic vessels }\end{array}$ \\
3 & $\begin{array}{l}\text { Severe steatosis; severely increased echogenicity of liver parenchyma; poor or no visualization of diaphragm and intrahepatic } \\
\text { vessels and posterior part of the right liver lobe }\end{array}$
\end{tabular}

EASO (104), US is the preferred first-line diagnostic procedure for imaging of NAFLD. US evaluation of HS typically consists of a qualitative visual assessment of hepatic echogenicity (107), evaluation of echo penetration into the deep portion of the liver, the relative echogenicity of the liver to the kidney and determination of the clarity of blood vessel structures in the liver. Normally, liver echogenicity equals or slightly exceeds renal cortical echogenicity, while fatty liver has higher echogenicity ("bright liver") than renal cortex and splenic parenchyma, due to intracellular fat vacuole accumulation, and intra-hepatic vascular blurring $(107,108)$.

To overcome the limitations of the conventional qualitative evaluation, quantitative ultrasound (QUS) parameters, including attenuation coefficient and backscatter coefficient (BSC) $(109,110)$, have been developed and studied. This methodology overcomes previous limitations of conventional qualitative US because QUS parameters are estimated using a reference phantom and objective computer algorithms. Thus, the phantom reference addresses machine (transducer format, gain, dynamic range, focusing, frequency, etc.) and operator dependencies, therefore helping to reduce both sources of variability (111-113). Ultrasound signals, that depend on tissue microstructure, can be analyzed using two methods: (I) spectral-based parameterization of the signals (that focuses on estimation of the BSC as a starting point from which additional QUS estimates are calculated); (II) characterization of the envelope statistics (113). BSC is defined as the differential scattering cross section per unit volume for a scattering angle of $180^{\circ}(114)$; it is related to the underlying tissue structure and, similarly to the attenuation, is a fundamental property of tissue (115). Attenuation is the loss of energy of an US signal as it is propagated through a tissue (116) and an attenuation coefficient can be estimated from the ultrasonic backscattered RF data (117). Information about the tissue microstructural properties can be extracted from the envelope of backscattered RF signals. Several models for the statistics of the envelope have been proposed and investigated, such as Nakagami and homodyned-K (HK) distributions with promising although not conclusive results $(118,119)$.

\section{Clinical significance}

With US qualitative assessment of HS, severity is usually graded clinically using a four-point scale, as follows: normal (grade 0), mild (grade 1), moderate (grade 2), and severe (grade 3) $(120,121)$ (Table 7). However such qualitative subjective evaluation presents low sensitivity (steatosis $<20 \%$ is not reliably detected) $(120,122)$, low specificity and substantial observer variability. According to Strauss et al. (123) mean inter-observer and intra-observer agreement rates for the presence of fatty liver were $72 \%(\mathrm{kappa}=0.43)$ and $76 \%(\mathrm{kappa}=0.54)$, while intra-observer agreement for severity of fatty liver ranged from $55 \%$ to $68 \%$ (kappa $=0.51-0.63)$. Moreover, it cannot distinguish between NAFLD and NASH. Several recent inter-laboratory studies demonstrated that QUS methods in reference phantoms and in vivo using clinical imaging scanners are highly reproducible and independent of operator and imaging system factors. QUS BSC showed robust correlation with MRI-PDFF towards the degree of HS and the identification of patients with NAFLD (sensitivity: 87-93\%; specificity: 91-93\%) with potential for noninvasive quantification of liver fat content. Several studies have shown a strong correlation between the attenuation coefficient and the amount of fat in the liver measured by MRI-PDFF and demonstrated, although values were different among different works, a higher attenuation for fatty liver than that in normal liver (116,124-127). 


\section{Conclusions}

US is a fast, close-at-hand, low cost and widely available technology. It demonstrated a good accuracy and reproducibility, which can be considered acceptable for most screening and clinical intents. Operators can be trained relatively easily and quickly. However, some features may represent a significant limitation in longitudinal evaluation of patients which are expected to have only mild changes in weight and BC. It can regionally distinguish between visceral and subcutaneous fat depots and can assess lipid storage within organs, such as liver and muscle. The association between visceral fat thickness measured by ultrasound and the metabolic risk factors of CVD is more pronounced than the associations between these factors and anthropometric parameters (BMI and WC). It can be used from infancy, making this technique a feasible and valuable method for the assessment of possible risk factors associated with obesity in a very early stage. US is a valid tool to assess subcutaneous fat thicknesses due to its high repeatability and precision. This technique has the advantage that measures can be taken in participants with severe obesity at sites not amenable to skinfold measures. Ultrasound has the advantage of being able to assess both skeletal muscle quantity (measurements of muscle thickness and CSA) and quality (measurements of PA and echogenicity), supporting the diagnosis of sarcopenia in older adults. It is a valid method for detecting the presence or absence of liver steatosis when compared to the gold standard method (liver biopsy) and the reference imaging methods, such as CT and MRI.

Alongside the "traditional" qualitative US evaluation, more recently the QUS measurements (attenuation coefficient, BSC) have shown great potential in quantify HS and to screen the population for NAFLD although further investigations are needed to translate QUS from research into the clinical practice. There are no risks related to ionizing radiation for patients, but this method is more operator-dependent than other techniques. The training of the operator, the light pressure of the probe on the skin, the supine positioning and respiratory condition of the patients as well as the fasting period before the examination, if not carefully performed, could lead to a decrease in accuracy and inter- and intra-operator agreement. Although the use of US in the field of $\mathrm{BC}$ appears promising this technique pose some problems. In particular, there is currently a lack of a clear and standardized protocol for the assessment of FM and LM, including: (I) no widely established norms for the various muscle and adipose tissue US parameters within the healthy population; (II) there is no definitive agreement either about which muscle groups or fat compartments should be measured or the probe sites; (III) there is no defined criteria for low skeletal muscle mass or its impaired quality identification in sarcopenia as well as there is not consolidated quantitative reference values of fat parameters discriminating population at cardio-metabolic risk.

Due to lack of evidence on absolute validity or consolidated reference values, US should be used with caution when more accurate measures of fat distribution are required, for instance in individuals with specific conditions (e.g., lipodystrophy). For these cases, the use of other heavier imaging technique (MRI, CT and DXA) is preferred. The heterogeneity of US methods that could be adopted for BC measurement and analysis could impact on future clinical and research implementation, thus it is imperative that a standardized and easily applied technique is agreed on. US has the potential to become the first-line diagnostic imaging tool in the evaluation of $\mathrm{BC}$, especially in muscle-liver-adipose tissue axis, with a major impact on the management of metabolic diseases, including obesity and sarcopenia.

\section{Acknowledgments}

Funding: None.

\section{Footnote}

Provenance and Peer Review: With the arrangement by the Guest Editors and the editorial office, this article has been reviewed by external peers.

Conflicts of Interest: All authors have completed the ICMJE uniform disclosure form (available at http://dx.doi. org/10.21037/qims-19-1048). The special issue "Body Composition Imaging" was commissioned by the editorial office without any funding or sponsorship. GG served as the unpaid Guest Editor of the special issue and serves as an unpaid editorial board member of Quantitative Imaging in Medicine and Surgery. AB served as the unpaid Guest Editor of the special issue. The authors have no other conflicts of interest to declare.

Open Access Statement: This is an Open Access article distributed in accordance with the Creative Commons Attribution-NonCommercial-NoDerivs 4.0 International License (CC BY-NC-ND 4.0), which permits the non- 
commercial replication and distribution of the article with the strict proviso that no changes or edits are made and the original work is properly cited (including links to both the formal publication through the relevant DOI and the license). See: https://creativecommons.org/licenses/by-nc-nd/4.0/.

\section{References}

1. Chan JM, Rimm EB, Colditz GA, Stampfer MJ, Willett WC. Obesity, fat distribution, and weight gain as risk factors for clinical diabetes in men. Diabetes Care 1994;17:961-9.

2. Ginter E, Simko V. Becoming overweight: is there a health risk? Bratisl Lek Listy 2014;115:527-31.

3. Wang YC, McPherson K, Marsh T, Gortmaker SL, Brown $M$. Health and economic burden of the projected obesity trends in the USA and the UK. Lancet 2011;378:815-25.

4. Golabi P, Fukui N, Paik J, Sayiner M, Mishra A, Younossi ZM. Mortality risk detected by atherosclerotic cardiovascular disease score in patients with nonalcoholic fatty liver disease. Hepatol Commun 2019;3:1050-60.

5. Mathieu P, Poirier P, Pibarot P, Lemieux I, Després JP. Visceral obesity: the link among inflammation, hypertension, and cardiovascular disease. Hypertension 2009;53:577-84.

6. Fei J, Mazzoccoli G. Epicardial fat is an important visceral adipose depot influencing cardiovascular disease and metabolic syndrome. J Clin Exp Cardiol 2013;4:e121.

7. Mazzoccoli G. Body composition: where and when. Eur J Radiol 2016;85:1456-60.

8. Beaudart C, Zaaria M, Pasleau F, Reginster JY, Bruyère O. Health outcomes of sarcopenia: a systematic review and meta-analysis. PLoS One 2017;12:e0169548.

9. Bazzocchi A, Diano D, Ponti F, Salizzoni E, Albisinni U, Marchesini G, Battista G. A 360-degree overview of body composition in healthy people: relationships among anthropometry, ultrasonography, and dual-energy x-ray absorptiometry. Nutrition 2014;30:696-701.

10. Guglielmi G, Ponti F, Agostini M, Amadori M, Battista G, Bazzocchi A. The role of DXA in sarcopenia. Aging Clin Exp Res 2016;28:1047-60.

11. Bazzocchi A, Filonzi G, Ponti F, Albisinni U, Guglielmi G, Battista G. Ultrasound: which role in body composition? Eur J Radiol 2016;85:1469-80.

12. Ponti F, Santoro A, Mercatelli D, Gasperini C, Conte M, Martucci M, Sangiorgi L, Franceschi C, Bazzocchi A. Aging and imaging assessment of body composition: from fat to facts. Front Endocrinol (Lausanne) 2020;10:861.
13. Bazzocchi A, Filonzi G, Ponti F, Amadori M, Sassi C, Salizzoni E, Albisinni U, Battista G. The role of ultrasonography in the evaluation of abdominal fat: analysis of technical and methodological issues. Acad Radiol 2013;20:1278-85.

14. Bazzocchi A, Filonzi G, Ponti F, Sassi C, Salizzoni E, Battista G, Canini R. Accuracy, reproducibility and repeatability of ultrasonography in the assessment of abdominal adiposity. Acad Radiol 2011;18:1133-43.

15. Ashwell M, Mayhew L, Richardson J, Rickayzen B. Waistto-height ratio is more predictive of years of life lost than body mass index. PLoS One 2014;9:e103483.

16. Müller MJ, Braun W, Enderle J, Bosy-Westphal A. Beyond BMI: conceptual issues related to overweight and obese patients. Obes Facts 2016;9:193-205.

17. Brambilla P, Bedogni G, Moreno LA, Goran MI, Gutin B, Fox KR, Peters DM, Barbeau P, De Simone M, Pietrobelli A. Crossvalidation of anthropometry against magnetic resonance imaging for the assessment of visceral and subcutaneous adipose tissue in children. Int J Obes (Lond) 2006;30:23-30.

18. Bellan M, Menegatti M, Ferrari C, Carnevale Schianca GP, Pirisi M. Ultrasound-assessed visceral fat and associations with glucose homeostasis and cardiovascular risk in clinical practice. Nutr Metab Cardiovasc Dis 2018;28:610-7.

19. Misra A, Wasir JS, Vikram NK. Waist circumference criteria for the diagnosis of abdominal obesity are not applicable uniformly to all populations and ethnic groups. Nutrition 2005;21:969-76.

20. Corrêa MM, Facchini LA, Thumé E, Oliveira ERA de, Tomasi E. The ability of waist-to-height ratio to identify health risk. Rev Saude Publica 2019;53:66.

21. Ashwell M, Gunn P, Gibson S. Waist-to-height ratio is a better screening tool than waist circumference and BMI for adult cardiometabolic risk factors: systematic review and meta-analysis. Obes Rev 2012;13:275-86.

22. Browning LM, Hsieh SD, Ashwell M. A systematic review of waist-to-height ratio as a screening tool for the prediction of cardiovascular disease and diabetes: 0.5 could be a suitable global boundary value. Nutr Res Rev 2010;23:247-69.

23. Koch E, Bravo M, Romero C, Diaz A, Castañeda H, Aguilera H, Nivelo M, Romero T. Estatura, factores de riesgo cardiovascular y riesgo de mortalidad en adultos: Proyecto San Francisco, Chile. Rev Chil Cardiol 2011;30:198-206.

24. McCarron P, Okasha M, McEwen J, Smith GD. Height in young adulthood and risk of death from cardiorespiratory 
disease: a prospective study of male former students of Glasgow University, Scotland. Am J Epidemiol 2002;155:683-7.

25. Alberti KGMM, Eckel RH, Grundy SM, Zimmet PZ, Cleeman JI, Donato KA, Fruchart JC, James WPT, Loria CM, Smith SC Jr, International Diabetes Federation Task Force on Epidemiology and Prevention; Hational Heart, Lung, and Blood Institute; American Heart Association; World Heart Federation; International Atherosclerosis Society; International Association for the Study of Obesity. Harmonizing the metabolic syndrome: a joint interim statement of the International Diabetes Federation Task Force on Epidemiology and Prevention; National Heart, Lung, and Blood Institute; American Heart Association; World Heart Federation; International Atherosclerosis Society; and International Association for the Study of Obesity. Circulation 2009;120:1640-5.

26. Armellini F, Zamboni M, Rigo L, Todesco T, BergamoAndreis IA, Procacci C, Bosello O. The contribution of sonography to the measurement of intra-abdominal fat. $\mathrm{J}$ Clin Ultrasound 1990;18:563-7.

27. Leite CC, Wajchenberg BL, Radominski R, Matsuda D, Cerri GG, Halpern A. Intra-abdominal thickness by ultrasonography to predict risk factors for cardiovascular disease and its correlation with anthropometric measurements. Metabolism 2002;51:1034-40.

28. De Lucia Rolfe E, Sleigh A, Finucane FM, Brage S, Stolk RP, Cooper C, Sharp SJ, Wareham NJ, Ong KK. Ultrasound measurements of visceral and subcutaneous abdominal thickness to predict abdominal adiposity among older men and women. Obesity (Silver Spring) 2010;18:625-31.

29. Stolk RP, Wink O, Zelissen PM, Meijer R, van Gils AP, Grobbee DE. Validity and reproducibility of ultrasonography for the measurement of intraabdominal adipose tissue. Int J Obes Relat Metab Disord 2001;25:1346-51.

30. Gradmark AMI, Rydh A, Renström F, De Lucia-Rolfe E, Sleigh A, Nordström P, Brage S, Franks PW. Computed tomography-based validation of abdominal adiposity measurements from ultrasonography, dual-energy X-ray absorptiometry and anthropometry. Br J Nutr 2010;104:582-8.

31. Vlachos IS, Hatziioannou A, Perelas A, Perrea DN. Sonographic assessment of regional adiposity. AJR Am J Roentgenol 2007;189:1545-53.

32. Tornaghi G, Raiteri R, Pozzato C, Rispoli A, Bramani M, Cipolat M, Craveri A. Anthropometric or ultrasonic measurements in assessment of visceral fat? A comparative study. Int J Obes Relat Metab Disord 1994;18:771-5.

33. Liu KH, Chan YL, Chan WB, Kong WL, Kong MO, Chan JCN. Sonographic measurement of mesenteric fat thickness is a good correlate with cardiovascular risk factors: comparison with subcutaneous and preperitoneal fat thickness, magnetic resonance imaging and anthropometric indexes. Int J Obes Relat Metab Disord 2003;27:1267-73.

34. Kim SK, Kim HJ, Hur KY, Choi SH, Ahn CW, Lim SK, Kim KR, Lee HC, Huh KB, Cha BS. Visceral fat thickness measured by ultrasonography can estimate not only visceral obesity but also risks of cardiovascular and metabolic diseases. Am J Clin Nutr 2004;79:593-9.

35. Hamagawa K, Matsumura Y, Kubo T, Hayato K, Okawa M, Tanioka K, Yamasaki N, Kitaoka H, Yabe T, Nishinaga M, Doi YL. Abdominal visceral fat thickness measured by ultrasonography predicts the presence and severity of coronary artery disease. Ultrasound Med Biol 2010;36:1769-75.

36. Suzuki R, Watanabe S, Hirai Y, Akiyama K, Nishide T, Matsushima Y, Murayama H, Ohshima H, Shinomiya M, Shirai K. Abdominal wall fat index, estimated by ultrasonography, for assessment of the ratio of visceral fat to subcutaneous fat in the abdomen. Am J Med 1993;95:309-14.

37. Iacobellis G, Assael F, Ribaudo MC, Zappaterreno A, Alessi G, Di Mario U, Leonetti F. Epicardial fat from echocardiography: a new method for visceral adipose tissue prediction. Obes Res 2003;11:304-10.

38. Iacobellis G, Willens HJ. Echocardiographic epicardial fat: a review of research and clinical applications. J Am Soc Echocardiogr 2009;22:1311-9; quiz 1417-8.

39. Kawasaki S, Aoki K, Hasegawa O, Numata K, Tanaka K, Shibata N, Shimada S, Okamura A, Terauchi Y. Sonographic evaluation of visceral fat by measuring paraand perirenal fat. J Clin Ultrasound 2008;36:129-33.

40. Gong W, Ren H, Tong H, Shen X, Luo J, Chen S, Lai J, Chen X, Chen H, Yu W. A comparison of ultrasound and magnetic resonance imaging to assess visceral fat in the metabolic syndrome. Asia Pac J Clin Nutr 2007;16 Suppl $1: 339-45$.

41. Ribeiro-Filho FF, Faria AN, Azjen S, Zanella M-T, Ferreira SRG. Methods of estimation of visceral fat: advantages of ultrasonography. Obes Res 2003;11:1488-94.

42. Oh J, Kim SK, Shin DK, Park KS, Park SW, Cho YW. A simple ultrasound correlate of visceral fat. Ultrasound Med Biol 2011;37:1444-51. 
43. Mazzoccoli G, Dagostino MP, Vinciguerra M, Ciccone F, Paroni G, Seripa D, Addante F, Montella RC, De Cosmo S, Sera F, Greco A. An association study between epicardial fat thickness and cognitive impairment in the elderly. Am J Physiol Heart Circ Physiol 2014;307:H1269-76.

44. Stolk RP, Meijer R, Mali WPTM, Grobbee DE, van der Graaf Y, Secondary Manifestations of Arterial Disease Study Group. Ultrasound measurements of intraabdominal fat estimate the metabolic syndrome better than do measurements of waist circumference. Am J Clin Nutr 2003;77:857-60.

45. Bertoli S, Leone A, Vignati L, Spadafranca A, Bedogni G, Vanzulli A, Rodeschini E, Battezzati A. Metabolic correlates of subcutaneous and visceral abdominal fat measured by ultrasonography: a comparison with waist circumference. Nutr J 2016;15:2.

46. Li LX, Dong XH, Li MF, Zhang R, Li TT, Shen J, Shen J, Bao YQ, Jia WP. Serum uric acid levels are associated with hypertension and metabolic syndrome but not atherosclerosis in Chinese inpatients with type 2 diabetes. J Hypertens 2015;33:482-90; discussion 490.

47. Nagahama K, Inoue T, Kohagura K, Kinjo K, Ohya Y. Associations between serum uric acid levels and the incidence of hypertension and metabolic syndrome: a 4-year follow-up study of a large screened cohort in Okinawa, Japan. Hypertens Res 2015;38:213-8.

48. Lee YJ, Cho S, Kim SR. A possible role of serum uric acid as a marker of metabolic syndrome. Intern Med J 2014;44:1210-6.

49. Jena D, Choudhury AK, Mangaraj S, Singh M, Mohanty BK, Baliarsinha AK. Study of visceral and subcutaneous abdominal fat thickness and its correlation with cardiometabolic risk factors and hormonal parameters in polycystic ovary syndrome. Indian J Endocrinol Metab 2018;22:321-7.

50. Thaware PK, Patterson CC, Young IS, Casey C, McCance DR. Clinical utility of ultrasonography-measured visceral adipose tissue depth as a tool in early pregnancy screening for gestational diabetes: a proof-of-concept study. Diabet Med 2019;36:898-901.

51. Tadokoro N, Murano S, Nishide T, Suzuki R, Watanabe S, Murayama H, Morisaki N, Saito Y. Preperitoneal fat thickness determined by ultrasonography is correlated with coronary stenosis and lipid disorders in non-obese male subjects. Int J Obes Relat Metab Disord 2000;24:502-7.

52. Tayama K, Inukai T, Shimomura Y. Preperitoneal fat deposition estimated by ultrasonography in patients with non-insulin-dependent diabetes mellitus. Diabetes Res
Clin Pract 1999;43:49-58.

53. Liu KH, Chan YL, Chan WB, Chan JCN, Chu CWW. Mesenteric fat thickness is an independent determinant of metabolic syndrome and identifies subjects with increased carotid intima-media thickness. Diabetes Care 2006;29:379-84.

54. Cabrera-Rego JO, Iacobellis G, Castillo-Herrera JA, Valiente-Mustelier J, Gandarilla-Sarmientos JC, MarínJuliá SM, Navarrete-Cabrera J. Epicardial fat thickness correlates with carotid intima-media thickness, arterial stiffness, and cardiac geometry in children and adolescents. Pediatr Cardiol 2014;35:450-6.

55. Bazzocchi A, Ponti F, Diano D, Moio A, Albisinni U, Pasquali R, Battista G. Abdominal adiposity by ultrasonography: a "pocket" database for reference standard in Italian people. Prim Care Diabetes 2014;8:358-64.

56. Novais RLR, Café ACC, Morais AA, Bila WC, Santos GD da S, Lopes CA de O, Belo VS, Romano MCC, Lamounier JA. Intra-abdominal fat measurement by ultrasonography: association with anthropometry and metabolic syndrome in adolescents. J Pediatr (Rio J) 2019;95:342-9.

57. Müller W, Lohman TG, Stewart AD, Maughan RJ, Meyer NL, Sardinha LB, Kirihennedige N, ReguantClosa A, Risoul-Salas V, Sundgot-Borgen J, Ahammer H, Anderhuber F, Fürhapter-Rieger A, Kainz P, Materna W, Pilsl U, Pirstinger W, Ackland TR. Subcutaneous fat patterning in athletes: selection of appropriate sites and standardisation of a novel ultrasound measurement technique: ad hoc working group on body composition, health and performance, under the auspices of the IOC Medical Commission. Br J Sports Med 2016;50:45-54.

58. Toomey C, McCreesh K, Leahy S, Jakeman P. Technical considerations for accurate measurement of subcutaneous adipose tissue thickness using B-mode ultrasound. Ultrasound 2011;19:91-6.

59. Störchle P, Müller W, Sengeis M, Ahammer H, FürhapterRieger A, Bachl N, Lackner S, Mörkl S, Holasek S.

Standardized ultrasound measurement of subcutaneous fat patterning: high reliability and accuracy in groups ranging from lean to obese. Ultrasound Med Biol 2017;43:427-38.

60. El-Brawany MA, Nassiri DK, Terhaar G, Shaw A, Rivens I, Lozhken K. Measurement of thermal and ultrasonic properties of some biological tissues. J Med Eng Technol 2009;33:249-56.

61. Herman IP. Physics of the human body. Berlin Heidelberg: Springer-Verlag, 2007.

62. Bazzocchi A, Diano D, Ponti F, Andreone A, Sassi C, 
Albisinni U, Marchesini G, Battista G. Health and ageing: a cross-sectional study of body composition. Clin Nutr 2013;32:569-78.

63. Bazzocchi A, Ponti F, Cariani S, Diano D, Leuratti L, Albisinni U, Marchesini G, Battista G. Visceral fat and body composition changes in a female population after RYGBP: a two-year follow-up by DXA. Obes Surg 2015;25:443-51.

64. Snijder MB, Visser M, Dekker JM, Goodpaster BH, Harris TB, Kritchevsky SB, De Rekeneire N, Kanaya AM, Newman AB, Tylavsky FA, Seidell JC, Health ABC Study. Low subcutaneous thigh fat is a risk factor for unfavourable glucose and lipid levels, independently of high abdominal fat. The Health ABC Study. Diabetologia 2005;48:301-8.

65. Porter SA, Massaro JM, Hoffmann U, Vasan RS, O'Donnel CJ, Fox CS. Abdominal subcutaneous adipose tissue: a protective fat depot? Diabetes Care 2009;32:1068-75.

66. Kim D, Chung GE, Kwak MS, Seo HB, Kang JH, Kim W, Kim YJ, Yoon JH, Lee HS, Kim CY. Body fat distribution and risk of incident and regressed nonalcoholic fatty liver disease. Clin Gastroenterol Hepatol 2016;14:132-8.e4.

67. Jung CH, Kim BY, Kim KJ, Jung SH, Kim CH, Kang SK, Mok JO. Contribution of subcutaneous abdominal fat on ultrasonography to carotid atherosclerosis in patients with type 2 diabetes mellitus. Cardiovasc Diabetol 2014;13:67.

68. Cruz-Jentoft AJ, Bahat G, Bauer J, Boirie $Y$, Bruyère $O$, Cederholm T, Cooper C, Landi F, Rolland Y, Sayer AA, Schneider SM, Sieber CC, Topinkova E, Vandewoude M, Visser M, Zamboni M, Writing Group for the European Working Group on Sarcopenia in Older People 2 (EWGSOP2), and the Extended Group for EWGSOP2. Sarcopenia: revised European consensus on definition and diagnosis. Age Ageing 2019;48:16-31.

69. Mourtzakis M, Wischmeyer P. Bedside ultrasound measurement of skeletal muscle. Curr Opin Clin Nutr Metab Care 2014;17:389-95.

70. Seymour JM, Ward K, Sidhu PS, Puthucheary Z, Steier J, Jolley CJ, Rafferty G, Polkey MI, Moxham J. Ultrasound measurement of rectus femoris cross-sectional area and the relationship with quadriceps strength in COPD. Thorax 2009;64:418-23.

71. Tillquist M, Kutsogiannis DJ, Wischmeyer PE, Kummerlen C, Leung R, Stollery D, Karvellas CJ, Preiser JC, Bird N, Kozar R, Heyland DK. Bedside ultrasound is a practical and reliable measurement tool for assessing quadriceps muscle layer thickness. JPEN J Parenter Enteral Nutr 2014;38:886-90.
72. Reid CL, Campbell IT, Little RA. Muscle wasting and energy balance in critical illness. Clin Nutr 2004;23:273-80.

73. Toledo DO, Silva DC de LE, Santos DMD, Freitas BJ de, Dib R, Cordioli RL, Figueiredo EJ de A, Piovacari SMF, Silva JM. Bedside ultrasound is a practical measurement tool for assessing muscle mass. Rev Bras Ter Intensiva 2017;29:476-80.

74. Parry SM, El-Ansary D, Cartwright MS, Sarwal A, Berney S, Koopman R, Annoni R, Puthucheary Z, Gordon IR, Morris PE, Denehy L. Ultrasonography in the intensive care setting can be used to detect changes in the quality and quantity of muscle and is related to muscle strength and function. J Crit Care 2015;30:1151.e9-14.

75. Minetto MA, Caresio C, Menapace T, Hajdarevic A, Marchini A, Molinari F, Maffiuletti NA. Ultrasound-based detection of low muscle mass for diagnosis of sarcopenia in older adults. PM R 2016;8:453-62.

76. Strasser EM, Draskovits T, Praschak M, Quittan M, Graf A. Association between ultrasound measurements of muscle thickness, pennation angle, echogenicity and skeletal muscle strength in the elderly. Age (Dordr) 2013;35:2377-88.

77. Arts IMP, Pillen S, Schelhaas HJ, Overeem S, Zwarts MJ. Normal values for quantitative muscle ultrasonography in adults. Muscle Nerve 2010;41:32-41.

78. Ema R, Wakahara T, Mogi Y, Miyamoto N, Komatsu T, Kanehisa H, Kawakami Y. In vivo measurement of human rectus femoris architecture by ultrasonography: validity and applicability. Clin Physiol Funct Imaging 2013;33:267-73.

79. Gruther W, Benesch T, Zorn C, Paternostro-Sluga T, Quittan M, Fialka-Moser V, Spiss C, Kainberger F, Crevenna R. Muscle wasting in intensive care patients: ultrasound observation of the M. quadriceps femoris muscle layer. J Rehabil Med 2008;40:185-9.

80. Nishihara K, Kawai H, Kera T, Hirano H, Watanabe Y, Fujiwara Y, Ihara K, Kim H, Tanaka M, Obuchi S. Correlation of physical function with the thickness of multiple muscles of the quadriceps femoris in community-dwelling elderly individuals. Clin Interv Aging 2018;13:1945-51.

81. Watanabe Y, Yamada Y, Fukumoto Y, Ishihara T, Yokoyama K, Yoshida T, Miyake M, Yamagata E, Kimura $M$. Echo intensity obtained from ultrasonography images reflecting muscle strength in elderly men. Clin Interv Aging 2013;8:993-8.

82. Baldwin CE, Paratz JD, Bersten AD. Diaphragm and 
peripheral muscle thickness on ultrasound: intrarater reliability and variability of a methodology using non-standard recumbent positions. Respirology 2011;16:1136-43.

83. Sanada K, Kearns CF, Midorikawa T, Abe T. Prediction and validation of total and regional skeletal muscle mass by ultrasound in Japanese adults. Eur J Appl Physiol 2006;96:24-31.

84. Abe T, Kondo M, Kawakami Y, Fukunaga T. Prediction equations for body composition of Japanese adults by B-mode ultrasound. Am J Hum Biol 1994;6:161-70.

85. Delaney S, Worsley P, Warner M, Taylor M, Stokes M. Assessing contractile ability of the quadriceps muscle using ultrasound imaging. Muscle Nerve 2010;42:530-8.

86. Narici M. Human skeletal muscle architecture studied in vivo by non-invasive imaging techniques: functional significance and applications. J Electromyogr Kinesiol 1999;9:97-103.

87. Kawakami Y, Abe T, Fukunaga T. Muscle-fiber pennation angles are greater in hypertrophied than in normal muscles. J Appl Physiol (1985) 1993;74:2740-4.

88. Zhu S, Lin W, Chen S, Qi H, Wang S, Zhang A, Cai J, Lai B, Sheng Y, Ding G. The correlation of muscle thickness and pennation angle assessed by ultrasound with sarcopenia in elderly Chinese community dwellers. Clin Interv Aging 2019;14:987-96.

89. Pillen S, van Dijk JP, Weijers G, Raijmann W, de Korte CL, Zwarts MJ. Quantitative gray-scale analysis in skeletal muscle ultrasound: a comparison study of two ultrasound devices. Muscle Nerve 2009;39:781-6.

90. Ata AM, Kara M, Kaymak B, Gürçay E, Çakır B, Ünlü H, Akıncı A, Özçakar L. Regional and total muscle mass, muscle strength and physical performance: the potential use of ultrasound imaging for sarcopenia. Arch Gerontol Geriatr 2019;83:55-60.

91. Puthucheary ZA, Rawal J, McPhail M, Connolly B, Ratnayake G, Chan P, Hopkinson NS, Phadke R, Padhke R, Dew T, Sidhu PS, Velloso C, Seymour J, Agley CC, Selby A, Limb M, Edwards LM, Smith K, Rowlerson A, Rennie MJ, Moxham J, Harridge SDR, Hart N, Montgomery HE. Acute skeletal muscle wasting in critical illness. JAMA 2013;310:1591-600.

92. Hughes VA, Frontera WR, Wood M, Evans WJ, Dallal GE, Roubenoff R, Fiatarone Singh MA. Longitudinal muscle strength changes in older adults: influence of muscle mass, physical activity, and health. J Gerontol A Biol Sci Med Sci 2001;56:B209-217.

93. Fukumoto Y, Ikezoe T, Yamada Y, Tsukagoshi R,
Nakamura M, Mori N, Kimura M, Ichihashi N. Skeletal muscle quality assessed from echo intensity is associated with muscle strength of middle-aged and elderly persons. Eur J Appl Physiol 2012;112:1519-25.

94. Osawa Y, Arai Y, Oguma Y, Hirata T, Abe Y, Azuma K, Takayama M, Hirose N. Relationships of muscle echo intensity with walking ability and physical activity in the very old population. J Aging Phys Act 2017;25:189-95.

95. Ye X, Wang M, Xiao H. Echo intensity of the rectus femoris in stable COPD patients. Int J Chron Obstruct Pulmon Dis 2017;12:3007-15.

96. Morse CI, Thom JM, Reeves ND, Birch KM, Narici MV. In vivo physiological cross-sectional area and specific force are reduced in the gastrocnemius of elderly men. J Appl Physiol (1985) 2005;99:1050-5.

97. Burt AD, Mutton A, Day CP. Diagnosis and interpretation of steatosis and steatohepatitis. Semin Diagn Pathol 1998;15:246-58.

98. Hamer OW, Aguirre DA, Casola G, Lavine JE, Woenckhaus M, Sirlin CB. Fatty liver: imaging patterns and pitfalls. Radiographics 2006;26:1637-53.

99. Chalasani N, Younossi Z, Lavine JE, Diehl AM, Brunt EM, Cusi K, Charlton M, Sanyal AJ. The diagnosis and management of non-alcoholic fatty liver disease: practice Guideline by the American Association for the Study of Liver Diseases, American College of Gastroenterology, and the American Gastroenterological Association. Hepatology 2012;55:2005-23.

100.Le MH, Devaki P, Ha NB, Jun DW, Te HS, Cheung RC, Nguyen MH. Prevalence of non-alcoholic fatty liver disease and risk factors for advanced fibrosis and mortality in the United States. PLoS One 2017;12:e0173499.

101. Bosserhoff A, Hellerbrand C. Obesity and fatty liver are "grease" for the machinery of hepatic fibrosis. Dig Dis 2011;29:377-83.

102. Sanyal AJ, Brunt EM, Kleiner DE, Kowdley KV, Chalasani N, Lavine JE, Ratziu V, McCullough A. Endpoints and clinical trial design for nonalcoholic steatohepatitis. Hepatology 2011;54:344-53.

103. Sanyal AJ, American Gastroenterological Association. AGA technical review on nonalcoholic fatty liver disease. Gastroenterology 2002;123:1705-25.

104. European Association for the Study of the Liver (EASL), European Association for the Study of Diabetes (EASD), European Association for the Study of Obesity (EASO). EASL-EASD-EASO Clinical Practice Guidelines for the management of non-alcoholic fatty liver disease. J Hepatol 2016;64:1388-402. 
105.Zhang YN, Fowler KJ, Hamilton G, Cui JY, Sy EZ, Balanay M, Hooker JC, Szeverenyi N, Sirlin CB. Liver fat imaging-a clinical overview of ultrasound, CT, and MR imaging. Br J Radiol 2018;91:20170959.

106. Kramer H, Pickhardt PJ, Kliewer MA, Hernando D, Chen G-H, Zagzebski JA, Reeder SB. Accuracy of liver fat quantification with advanced CT, MRI, and ultrasound techniques: prospective comparison with MR spectroscopy. AJR Am J Roentgenol 2017;208:92-100.

107. Lee SS, Park SH. Radiologic evaluation of nonalcoholic fatty liver disease. World J Gastroenterol 2014;20:7392-402.

108.Zwiebel WJ. Sonographic diagnosis of diffuse liver disease. Semin Ultrasound CT MR 1995;16:8-15.

109. Barr RG, Ferraioli G, Palmeri ML, Goodman ZD, GarciaTsao G, Rubin J, Garra B, Myers RP, Wilson SR, Rubens D, Levine D. Elastography assessment of liver fibrosis: society of radiologists in ultrasound consensus conference statement. Radiology 2015;276:845-61.

110.Lin SC, Heba E, Wolfson T, Ang B, Gamst A, Han A, Erdman JW, O'Brien WD, Andre MP, Sirlin CB, Loomba R. Noninvasive diagnosis of nonalcoholic fatty liver disease and quantification of liver fat using a new quantitative ultrasound technique. Clin Gastroenterol Hepatol 2015;13:1337-45.e6.

111.Paige JS, Bernstein GS, Heba E, Costa EAC, Fereirra M, Wolfson T, Gamst AC, Valasek MA, Lin GY, Han A, Erdman JW, O'Brien WD, Andre MP, Loomba R, Sirlin CB. A pilot comparative study of quantitative ultrasound, conventional ultrasound, and MRI for predicting histology-determined steatosis grade in adult nonalcoholic fatty liver disease. AJR Am J Roentgenol 2017;208:W168-77.

112. Yang KC, Liao YY, Tsui PH, Yeh CK. Ultrasound imaging in nonalcoholic liver disease: current applications and future developments. Quant Imaging Med Surg 2019;9:546-51.

113. Wirtzfeld LA, Ghoshal G, Hafez ZT, Nam K, Labyed Y, Anderson JJ, Herd M-T, Haak A, He Z, Miller RJ, Sarwate S, Simpson DG, Zagzebski JA, Bigelow TA, Oelze ML, Hall TJ, O’Brien WD. Cross-imaging platform comparison of ultrasonic backscatter coefficient measurements of live rat tumors. J Ultrasound Med 2010;29:1117-23.

114. Chen JF, Zagzebski JA, Madsen EL. Tests of backscatter coefficient measurement using broadband pulses. IEEE

Trans Ultrason Ferroelectr Freq Control 1993;40:603-7.

115.Nam K, Rosado-Mendez IM, Wirtzfeld LA, Pawlicki AD, Kumar V, Madsen EL, Ghoshal G, Lavarello RJ,
Oelze ML, Bigelow TA, Zagzebski JA, O’Brien WD, Hall TJ. Ultrasonic attenuation and backscatter coefficient estimates of rodent-tumor-mimicking structures: comparison of results among clinical scanners. Ultrason Imaging 2011;33:233-50.

116. Taylor KJ, Riely CA, Hammers L, Flax S, Weltin G, Garcia-Tsao G, Conn HO, Kuc R, Barwick KW. Quantitative US attenuation in normal liver and in patients with diffuse liver disease: importance of fat. Radiology 1986;160:65-71.

117. Andre MP, Han A, Heba E, Hooker J, Loomba R, Sirlin CB, Erdman JW, O'Brien WD. Accurate diagnosis of nonalcoholic fatty liver disease in human participants via quantitative ultrasound. Chicago: 2014 IEEE International Ultrasonics Symposium, 2014:2375-7.

118.Zhou Z, Zhang Q, Wu W, Wu S, Tsui PH. Hepatic steatosis assessment using quantitative ultrasound parametric imaging based on backscatter envelope statistics. Appl Sci 2019;9:661.

119.Zhou Z, Zhang Q, Wu W, Lin YH, Tai DI, Tseng JH, Lin YR, Wu S, Tsui PH. Hepatic steatosis assessment using ultrasound homodyned-K parametric imaging: the effects of estimators. Quant Imaging Med Surg 2019;9:1932-47.

120.Saadeh S, Younossi ZM, Remer EM, Gramlich T, Ong JP, Hurley M, Mullen KD, Cooper JN, Sheridan MJ. The utility of radiological imaging in nonalcoholic fatty liver disease. Gastroenterology 2002;123:745-50.

121. Saverymuttu SH, Joseph AE, Maxwell JD. Ultrasound scanning in the detection of hepatic fibrosis and steatosis. Br Med J (Clin Res Ed) 1986;292:13-5.

122. Fishbein M, Castro F, Cheruku S, Jain S, Webb B, Gleason T, Stevens WR. Hepatic MRI for fat quantitation: its relationship to fat morphology, diagnosis, and ultrasound. J Clin Gastroenterol 2005;39:619-25.

123. Strauss S, Gavish E, Gottlieb P, Katsnelson L. Interobserver and intraobserver variability in the sonographic assessment of fatty liver. AJR Am J Roentgenol 2007;189:W320-3.

124.Lin T, Ophir J, Potter G. Correlation of ultrasonic attenuation with pathologic fat and fibrosis in liver disease. Ultrasound Med Biol 1988;14:729-34.

125.Lu ZF, Zagzebski JA, Lee FT. Ultrasound backscatter and attenuation in human liver with diffuse disease. Ultrasound Med Biol 1999;25:1047-54.

126. Fujii Y, Taniguchi N, Itoh K, Shigeta K, Wang Y, Tsao JW, Kumasaki K, Itoh T. A new method for attenuation coefficient measurement in the liver: comparison with the spectral shift central frequency method. J Ultrasound Med 
2002;21:783-8.

127. Thijssen JM, Starke A, Weijers G, Haudum A, Herzog K, Wohlsein P, Rehage J, De Korte CL. Computer- aided B-mode ultrasound diagnosis of hepatic steatosis: a feasibility study. IEEE Trans Ultrason Ferroelectr Freq Control 2008;55:1343-54.

Cite this article as: Ponti F, De Cinque A, Fazio N, Napoli A, Guglielmi G, Bazzocchi A. Ultrasound imaging, a stethoscope for body composition assessment. Quant Imaging Med Surg 2020;10(8):1699-1722. doi: 10.21037/qims-19-1048 